\title{
1 Controls on Geothermal Heat Recovery from a Hot Sedimentary 2 Aquifer in Guardbridge, Scotland: Field Measurements, Modelling 3 and Long Term Sustainability.
}

\section{A. Comerford, A. Fraser-Harris ${ }^{1}$, G. Johnson ${ }^{1}$, C. I. McDermott ${ }^{1}$}

\section{$6 \quad{ }^{1}$ University of Edinburgh, School of Geosciences, The King's Buildings, James Hutton} 7 Road, Edinburgh EH9 3FE.

\begin{abstract}
Geothermal heat from Hot Sedimentary Aquifers represents a promising intermediate $\left(30^{\circ} \mathrm{C}\right)$ resource for district heating systems. A key control on the geothermal productivity of these aquifers is the architecture of faults, which can significantly enhance or reduce the natural permeability of these systems. We present the first three-dimensional coupled groundwater flow and heat transport numerical model, combining multiple data from field mapping and fracture surveys, of two intersecting major fault systems in Central-East Scotland. This includes fault-zone fracture permeability modelling, depthdependent permeability modelling, geo-mechanical facies assessment and heat productivity estimates for single well and multiple well extraction scenarios. Simulations indicate that with careful location of extraction wells within permeable fault systems, production is sustainable for over 50 years for multiple-well extraction scenarios in this region.
\end{abstract}

Keywords: Geothermal; Hot Sedimentary Aquifers; Permeability; Fracture; Fault

\section{Introduction}

With the burgeoning need for renewable energy and the increasing costs of domestic heating, deep geothermal energy resources represent a promising low-carbon alternative to conventional hydrocarbon based heating. Low enthalpy geothermal resources are among the most widely available geothermal resources and provide huge potential for decarbonisation of the heating sector of the energy market (Gillespie, et al., 2013; Barker, et al., 2000). Here we refer to sedimentary aquifers that can yield economic quantities of warm water, either through primary or secondary permeability, as Hot Sedimentary Aquifers (HSAs). At depth, fracture systems can play an important role in determining the nature of fluid flow, therefore understanding their influence is key to predicting the geothermal productivity of rocks in the brittle crust used as low enthalpy resources, such as HSAs.

In the UK, the Upper Devonian to Carboniferous sedimentary rocks of the Scottish Midland Valley (SMV) show favourable characteristics as HSAs, with high intergranular productivity and a proximity to large population centres (MacDonald, et al., 2004). Central and East Scotland have been identified Abbreviations: $\mathrm{BH}=$ Borehole, $\mathrm{CW}=$ Circle Window (data sampling method), $\mathrm{DFN}=$ Discrete Fracture Network, DDF $=$ Dura Den Fault, FC $=$ Fault Core, FDZ $=$ Fault Damage Zone, HSA $=$ Hot Sedimentary Aquifer, KPF $=$ Knox Pulpit Formation, MRF $=$ Maiden Rock Fault, SMV $=$ Scottish Midland Valley 
as regions where geothermal district heating schemes could potentially satisfy a high proportion of the heat demand (Dumas \& Bartosik, 2014). The SMV is a failed rift system with widespread normal faulting where groundwater flow is partly governed by regional-scale faults and fracture systems (Ó Dochartaigh, 2004; Rippon, et al., 1996). The Strathden Group sandstones beneath the River Eden catchment in Fife in the eastern SMV have been found to be the most productive aquifers in the region (Browne, et al., 1985). These are cut by two intersecting fault systems - the Dura Den Fault (DDF) and Maiden Rock Fault (MRF) close to local population centres (Figure 1). Within the Strathden Group, the Knox Pulpit Formation (KPF) shows the highest transmissivity, particularly where enhanced by fracturing (Gaus \& Ó Dochartaigh, 2000; Ó Dochartaigh, 2004; MacDonald, et al., 2004; Ó Dochartaigh, et al., 2011). Shallow geophysical logging $(<200 \mathrm{~m})$ of 23 boreholes by Ó Dochartaigh (2004) showed that fracture flow is dominant in the KPF, constituting more than $70 \%$ its transmissivity. However, properties at deeper levels remain largely unknown within the Strathden Group (Gillespie, et al., 2013).

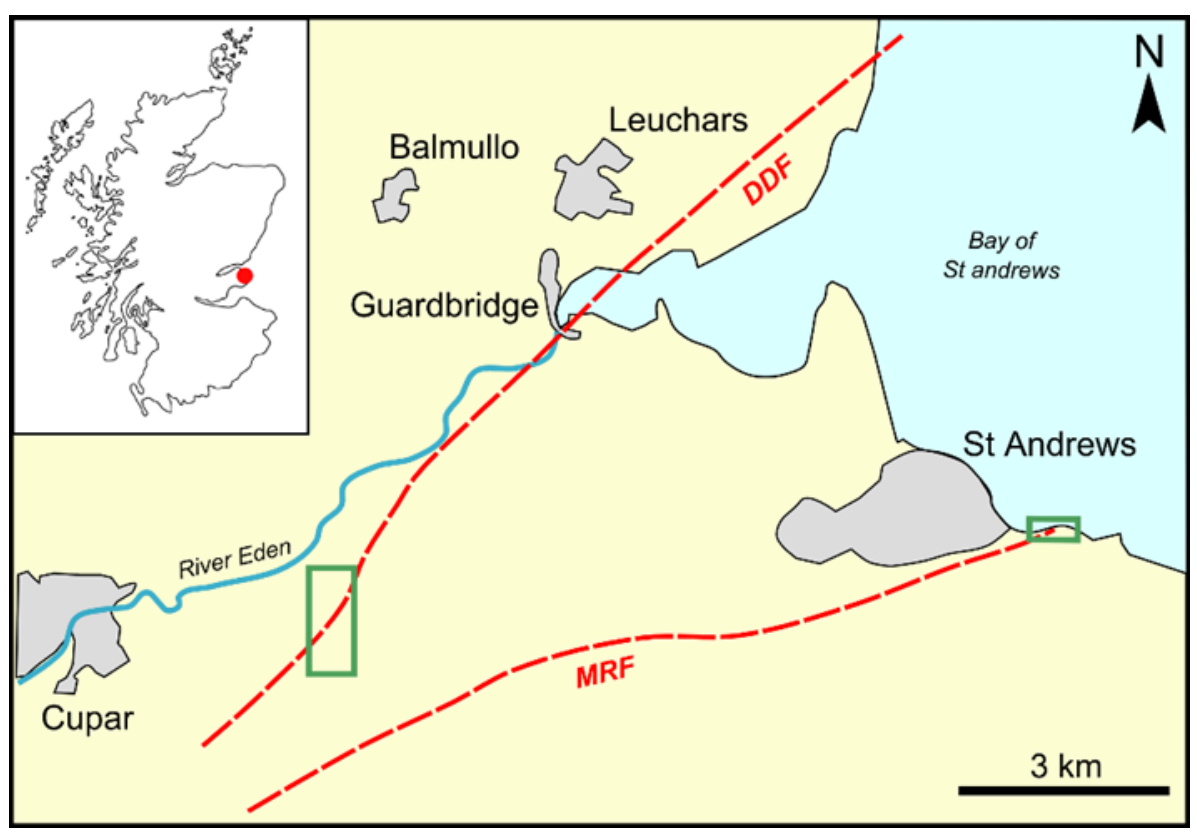

Figure 1: Overview Map of the Eden Catchment. DDF $=$ Dura Den Fault, MRF $=$ Maiden Rock Fault. Green rectangles indicate the field areas investigated in this study

Understanding fault architecture is therefore key to estimating the permeability and productivity within the KPF at depths suitable for geothermal extraction, as well as determining the potential siting of extraction wells. Fault zones, formed of concentrations of intersecting fracture sets, can variably inhibit or enhance fluid flow in multiple orientations on a crustal scale (Caine, et al., 1996). Previous studies of fault zone architecture (Forster \& Evans, 1991; Caine, et al., 1996; Childs, et al., 2009; Faulkner, et al., 2010) have identified two main fault permeability facies, namely the Fault Core (FC) and Fault Damage Zone (FDZ). The fault core, generally formed of clay-rich gouge and cataclasite, may be a single central plane of fault propagation or a more complex anastomosing structure with multiple 
strands (Faulkner, et al., 2010), whilst the damage zone surrounds the fault core and comprises fracture sets and discrete faults. The individual characteristics, relative dimensions, and distribution of the FC and FDZ within a fault zone control along- and across-fault permeability that may be incorporated into numerical models of geothermal systems e.g. (McDermott, et al., 2006a; McDermott, et al., 2006b; Watanabe, et al., 2010). The method of McDermott et al. (2006a) addresses fault architecture through the concept of geo-mechanical facies to distinguish the architectural elements of the fault core and damage zone with discrete flow, transport and mechanical characteristics. Within their model, hydraulic boundaries separated each section of the shear zone, with the FC, FDZ and host rock being allocated unique hydrogeological parameters (Figure 2).

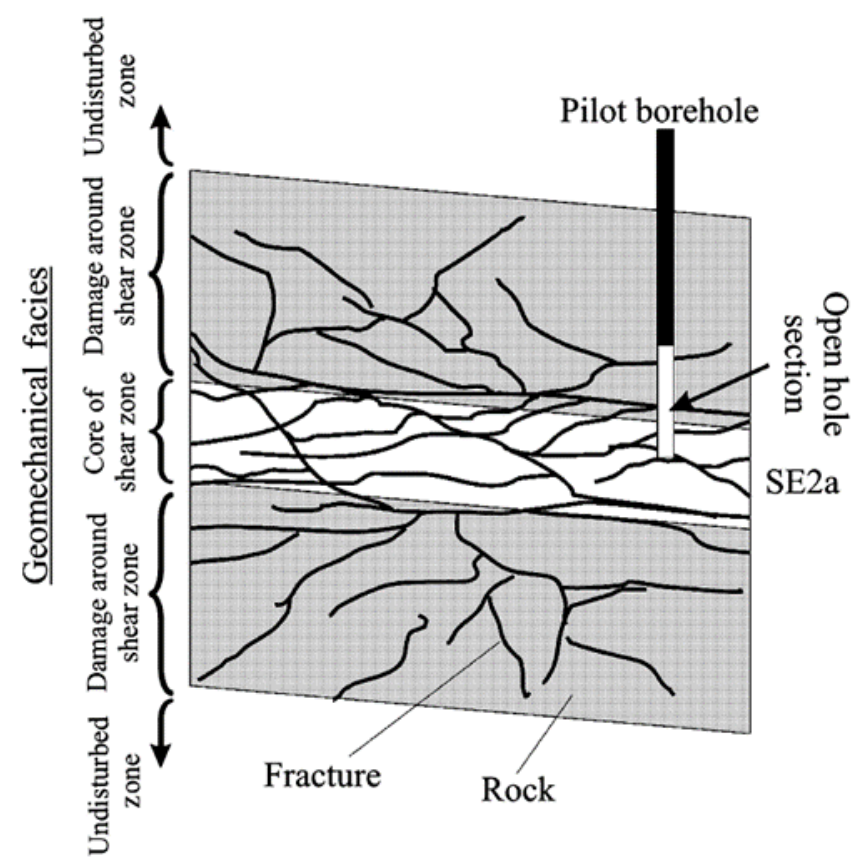

Figure 2: A conceptual 3D model of shear zones illustrating the concept of geo-mechanical facies (McDermott et al 2006). This concept is applied to modelling of the Dura Den and Maiden Rock Faults. Robinson et al. (2016) conducted a feasibility study into the commercial viability of a low enthalpy geothermal scheme as part of a district heating system that accesses the fault zone enhanced permeability of the KPF around the Dura Den Fault near Guardbridge, Fife. They conducted a sensitivity analysis using a two-dimensional groundwater model, investigating the hydraulic properties that would need to be encountered at depth for the geothermal project to be considered economic. However, they cite a dearth of structural data as a source of significant uncertainty for numerical modelling of the prospective geothermal project.

Here we address the lack of structural data identified by Robinson et al (2016) through detailed field mapping and fracture surveys of the two intersecting major faults in the region - the DDF and MRF. These data provide the input for discrete fracture network (DFN) modelling, providing permeability estimates for the fault damage zone of the DDF. These are incorporated into the first three-dimensional 
(3D) coupled thermo-hydraulic numerical model of the prospective resource. Through this investigation, a workflow was developed that also forms the structure of this paper:

1. Field study of fracture networks: Fracture Mapping and Circle Window Sampling

2. Analysis of Field data: Statistical analysis of field data to define input to Discrete Fracture Networks (DFN) modelling

3. DFN \& Permeability Modelling: Apply fracture attributes to generate DFN within a sample volume and output fracture permeability and scale.

4. Conceptual Hydrogeological Modelling: Collate structural, hydrogeological and field data to create a 3D conceptual model of the aquifer system

5. Numerical Finite Element Hydrogeological Modelling: 3D regional hydrogeological modelling to simulate hydraulic drawdown and heat flux over a 50-year extraction period

\section{Methods and Results}

\subsection{Overview of Regional Geology}

The regional geology around Guardbridge consists of a sequence of sedimentary and volcanic rocks from Lower Devonian to mid Carboniferous in age. Lowermost in the sequence are the Lower Devonian sediments of the Arbuthnott Group, consisting variably of sandstones, conglomerates and mudstones. Overlying these sediments is the $2000 \mathrm{~m}$ thick Ochil Volcanic Formation, consisting of volcaniclastic rocks and basaltic lavas. The Ochil Volcanic Formation is overlain by the Scone Sandstone Formation, with an average thickness of $300 \mathrm{~m}$ that consists predominantly of cross-bedded sandstones with subsidiary siltstones, mudstones and conglomerates (Browne, et al., 2002).

Overlying the Scone Sandstone Formation is the Glenvale Sandstone Formation, comprised of feldspathic sandstones with bands of siltstone and pebbles of silty mudstone (Browne, et al., 2002). Robinson et al (2016) calculate that the Glenvale Sandstone Formation has an average thickness of 600 $\mathrm{m}$ in the region of this study. Overlying the Glenvale Sandstone Formation are the most hydraulically productive units in the succession; the Upper Devonian Knox Pulpit Formation consisting of very fineto coarse-grained feldspathic sandstones of aeolian origin, and the Lower Carboniferous Kinnesswood Formation of cross-bedded sandstones (Ó Dochartaigh, 2004). In terms of the hydrogeology, the Kinnesswood Formation is often considered part of the 'Upper Devonian aquifer' in Fife (Ó Dochartaigh, 2004). The highly deformed Carboniferous rocks of the Inverclyde and Strathclyde groups are also present in the study area as they overlie the Upper Devonian sedimentary rocks to the south of the Dura Den Fault. 


\subsection{Field Studies: Fracture Mapping and Circle Window Sampling}

111 Two field localities were studied with the purpose of characterising the structures and fracture networks 112 associated with the Dura Den and Maiden Rock faults. Both faults underwent N-S extension in the late113 Carboniferous and trend c. $040^{\circ}$ and $070^{\circ}$ respectively.

114 The Dura Den Fault (DDF) is exposed in the Dura Den $\left(56^{\circ} 19^{\prime} 18 \mathrm{~N}, 2^{\circ} 56^{\prime} 41 \mathrm{~W}\right)$, a gorge-like landform $1153 \mathrm{~km}$ east of Cupar. This locality provides a $1 \mathrm{~km}$ long section across the fault, juxtaposing the 116 Inverclyde Group sandstones in the south with the Knox Pulpit Formation in the north (Figure 3A.).

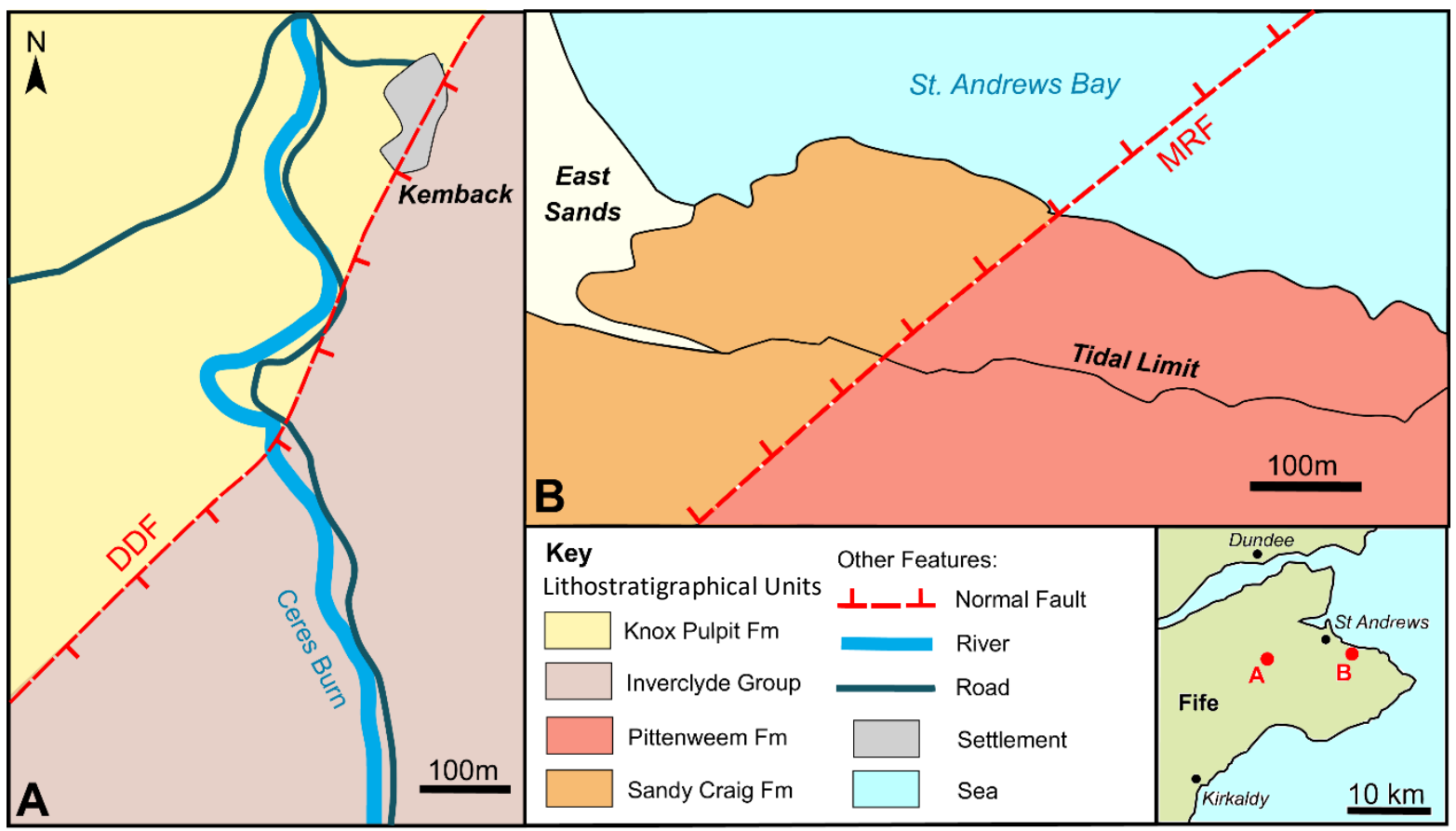

Figure 3: Overview maps of the two field sites and associated geological units. A: The Dura Den Fault (DDF) and B: The Maiden Rock Fault (MRF). Inset map shows the location of the two field study sites in Fife.

120 Exposure is widespread in cliffs and riverbeds, however surface erosion and vegetation often obscure or alter fracture characteristics.

The Maiden Rock Fault (MRF) is exposed as a coastal section 1km east of St Andrews (56 $16^{\circ} 56 \mathrm{~N}$, $2^{\circ} 46^{\prime} 13 \mathrm{~W}$ ) in cliffs and a wave-cut platform. At this locality, the MRF juxtaposes the Sandy Craig and Pittenweem formations of the Strathclyde Group Sandstones (Figure 3B.). Due to coastal erosion, exposure is heavily weathered and provides limited intact exposure.

Fracture mapping was used to collect a statistically significant population of fracture data $\left(\mathrm{nkm}^{-2}>100\right)$ at each field site. To provide insight into spatial variability of fracture data, the sampling area was roughly symmetrical around each fault. As fracture mapping does not compensate for orientation biases in data collection, circle window sampling was employed in parallel (Mauldon, 1998). The 'augmented circle window' method proposed by Watkins et al. (2015) was used, whereby fracture characteristics are noted for fractures intersecting the perimeter of a circular scan line. This specific method was 
selected to systematically mitigate biases and thus complement the indiscriminately mapped data.

133 The recorded data types and their implications for fluid flow are discussed in Table 1. Circle window sampling sites were on multiply orientated vertical rock faces distributed as a rough transect across each fault plane to highlight variation in fracture characteristics between the fault core, damage zone, and the undeformed strata.

\begin{tabular}{|c|c|c|}
\hline Data & Units and Examples & Implications for fluid flow \\
\hline Circle Window Location & $\begin{array}{l}\text { Grid reference, distance from } \\
\text { fault core }\end{array}$ & $\begin{array}{l}\text { The relative positioning of fractures within a fault } \\
\text { zone can be used to describe hydrogeological } \\
\text { facies associated with damage zone, fault core } \\
\text { and host lithologies }\end{array}$ \\
\hline Attitude* & $\begin{array}{l}\text { Dip/Dip direction (degrees, } \\
\text { azimuth) }\end{array}$ & $\begin{array}{l}\text { The orientation of a fracture and consistency of } \\
\text { orientation dictates the permeability anisotropy } \\
\text { associated with a fracture and its interaction with } \\
\text { regional stresses }\end{array}$ \\
\hline $\begin{array}{l}\text { Fracture type/Fracture } \\
\text { fill }\end{array}$ & $\begin{array}{l}\text { Tension fracture, shear } \\
\text { fracture, joint, dip-slip fault, } \\
\text { strike-slip fault, dyke, vein }\end{array}$ & $\begin{array}{l}\text { The type of a fracture, particularly with the } \\
\text { presence of infilling mineralisation or cataclastic } \\
\text { material, determines its capacity to accommodate } \\
\text { fluid flow }\end{array}$ \\
\hline Displacement/Aperture* & $\begin{array}{l}\text { Width of tension fracture } \\
\text { (aperture), shear fracture/fault } \\
\text { throw }(\mathrm{mm} / \mathrm{cm} / \mathrm{m})\end{array}$ & $\begin{array}{l}\text { Fracture permeability and porosity } \\
\text { The aperture is an indicator of the } \mathbf{3 D} \text { volume of } \\
\text { a fracture system and thus its capacity to act as } \\
\text { a conduit for fluid flow }\end{array}$ \\
\hline Trace length* & $\begin{array}{l}\text { The length of the line of } \\
\text { intersection with the rock } \\
\text { surface }(\mathrm{mm} / \mathrm{cm} / \mathrm{m}\end{array}$ & $\begin{array}{l}\text { Fracture length is important in determining the } \\
\text { scaling of a facture system and thus the potential } \\
\text { vertical or lateral extent of fluid transport }\end{array}$ \\
\hline Intensity* & $\begin{array}{l}\text { Number of fractures estimated } \\
\text { or measured per unit length } \\
\text { (per } \mathrm{mm} / \mathrm{cm} / \mathrm{m}) \text {. Can be used as } \\
\text { a proxy for volumetric intensity } \\
\left(\text { per } \mathrm{m}^{3}\right)\end{array}$ & $\begin{array}{l}\text { Fracture spacing/ fracture intensity is a key } \\
\text { determinant of the bulk fracture permeability e.g. } \\
\text { areas of intense fracturing behaving as a large- } \\
\text { scale conduit }\end{array}$ \\
\hline
\end{tabular}

Table 1: An overview of the fracture characteristics recorded in field studies and their influence on fluid flow. Quantitative data that is used as an input for fracture modelling is highlighted with and asterisk.

137 At the Dura Den Fault (DDF) site, 341 fracture data points were mapped (Figure 4A) and 14 Circle 138 Window (CW) surveys carried out in a transect across the fault (Figure 5). Fracture sets were observed 139 to be dominantly subvertical, interpreted as extensional fractures, with NW dipping antithetic shear 140 fractures also widespread. Circular scan line surveys (Figure 5) showed a $400 \mathrm{~m}$ wide fault damage zone with dominantly subvertical fracturing and infrequent shear fractures. Localised normal faults were prevalent in the fault core with antithetic shear fractures at around $1 \mathrm{~m}$ spacing. Most fractures within this study site were open, showing $<10 \%$ mineralisation that was limited to shear fractures. The extent of the FC and FDZ was determined from deformation intensity, with the FC highlighted by a prevalence of normal faulting, observed in CW's 8.4, 9.1, 9.6 and 9.7 (Figure 5). Observed fracture length was limited by the extent of exposure, therefore length observations represent a minimum estimate. Based on the definitions of Caine et al (1996), the overall hydrogeological character of this fault could be inferred to be a distributed conduit to fluid flow. 
149 At the Maiden Rock Fault (MRF) site, 140 fractures (Figure 4B) were mapped and nine CW surveys 150 carried out in a transect across the fault. Fractures in the area showed $>95 \% \mathrm{FeO}$ mineralisation - very 151 few open fractures were observed. Additionally the MRF core was observed to consist of a $6 \mathrm{~m}$ thick impermeable layer of clayey fault gouge with pockets of cataclasite. The FDZ extended for $50 \mathrm{~m}$ either side of the fault core, defined by pervasive subvertical fracturing and antithetic faulting (Figure 4). As the MRF was almost entirely mineralised, had a thick clay gouge and thus was expected to be largely impermeable, no further fracture characterisation was carried out. Figure 6 shows conceptual hydrogeological models of the Dura Den and Maiden Rock faults from field data, highlighting predominant fracture trends and the dimensions of the fault core and damage zones (Caine, et al., 1996).
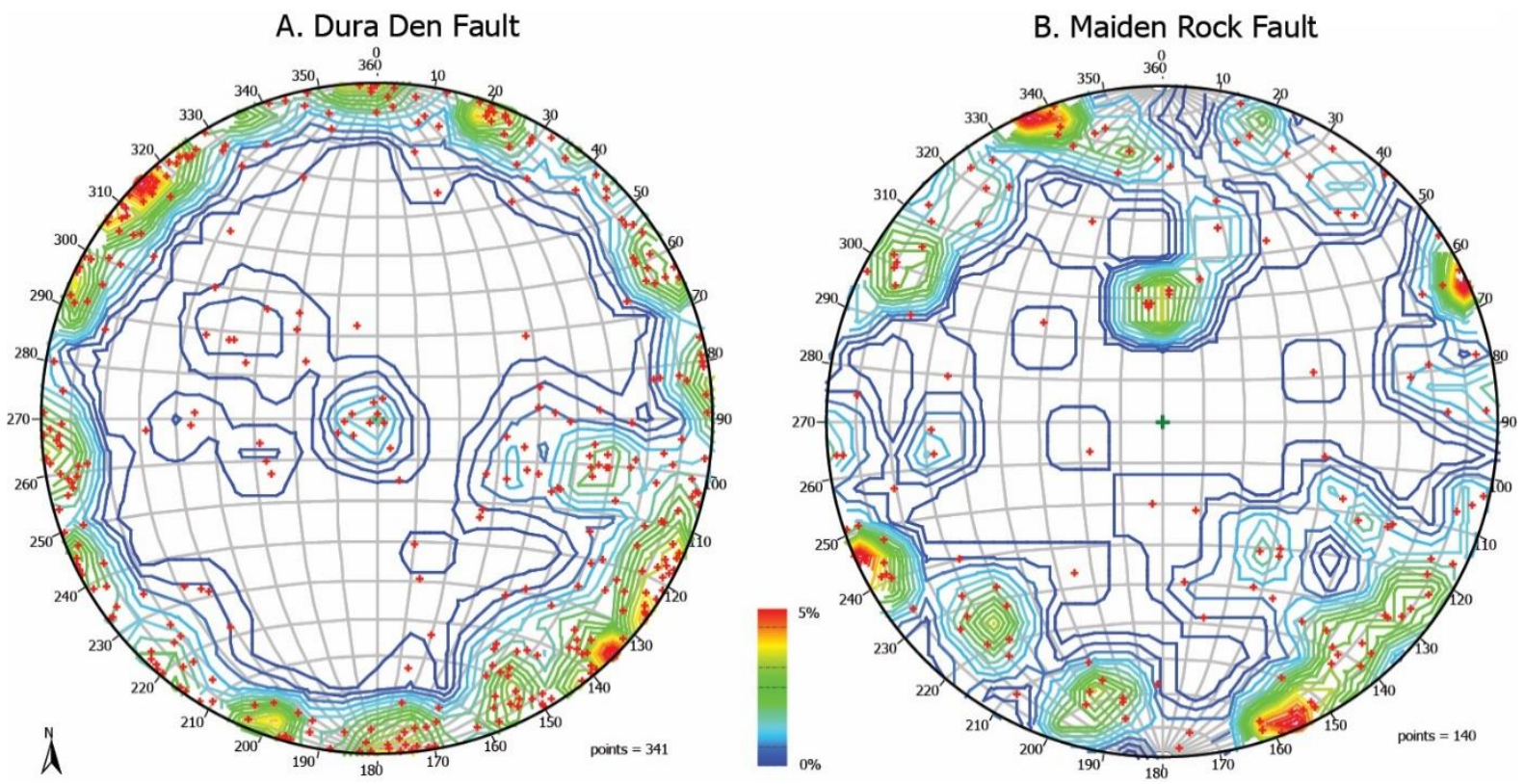

Figure 4: Contoured stereoplot of mapped poles to fracture planes, data from the Dura Den Fault ( $\mathrm{n}=341)$ and Maiden Rock Fault $(n=140)$ Red dots indicate individual fractures. Contour colour indicates density of data, in terms of percentage of total data points falling within a given $1 \%$ area of the plot with red indicating greatest $(5 \%)$ and blue the lowest $(0.4 \%)$. Contour interval $=0.4 \%$. 

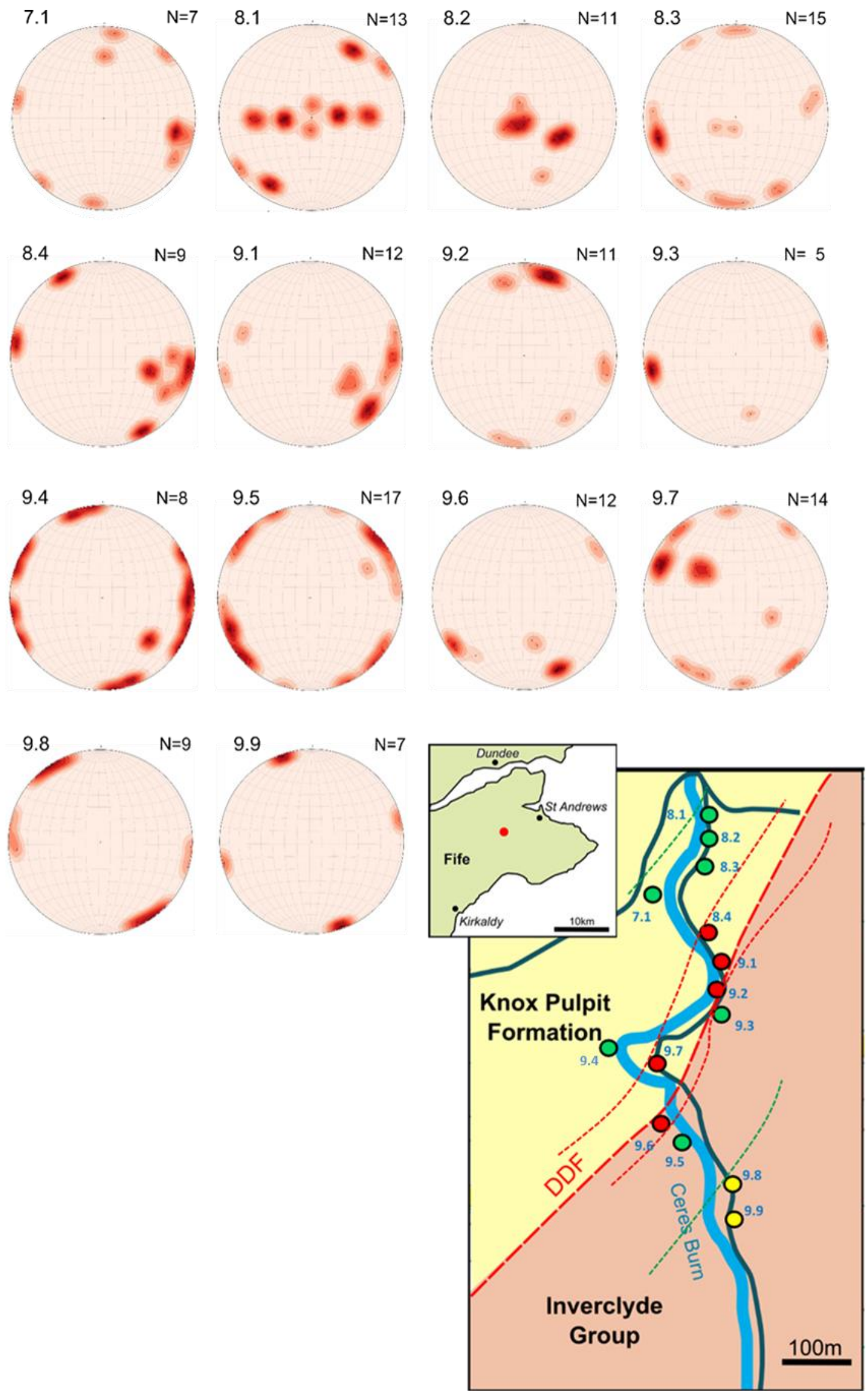

Figure 5: Circle window data stereo plots representing a rough transect across the Dura Den Fault. N: number of data points. Inset map: Location of the CW survey sites. Red dot: fault core, Green dot: Damage Zone, yellow dot: unfaulted strata. Red dashed line $=$ outer extent of fault core, green dashed line: Outer extent of damage zone. 


\section{Dura Den Fault Summary}

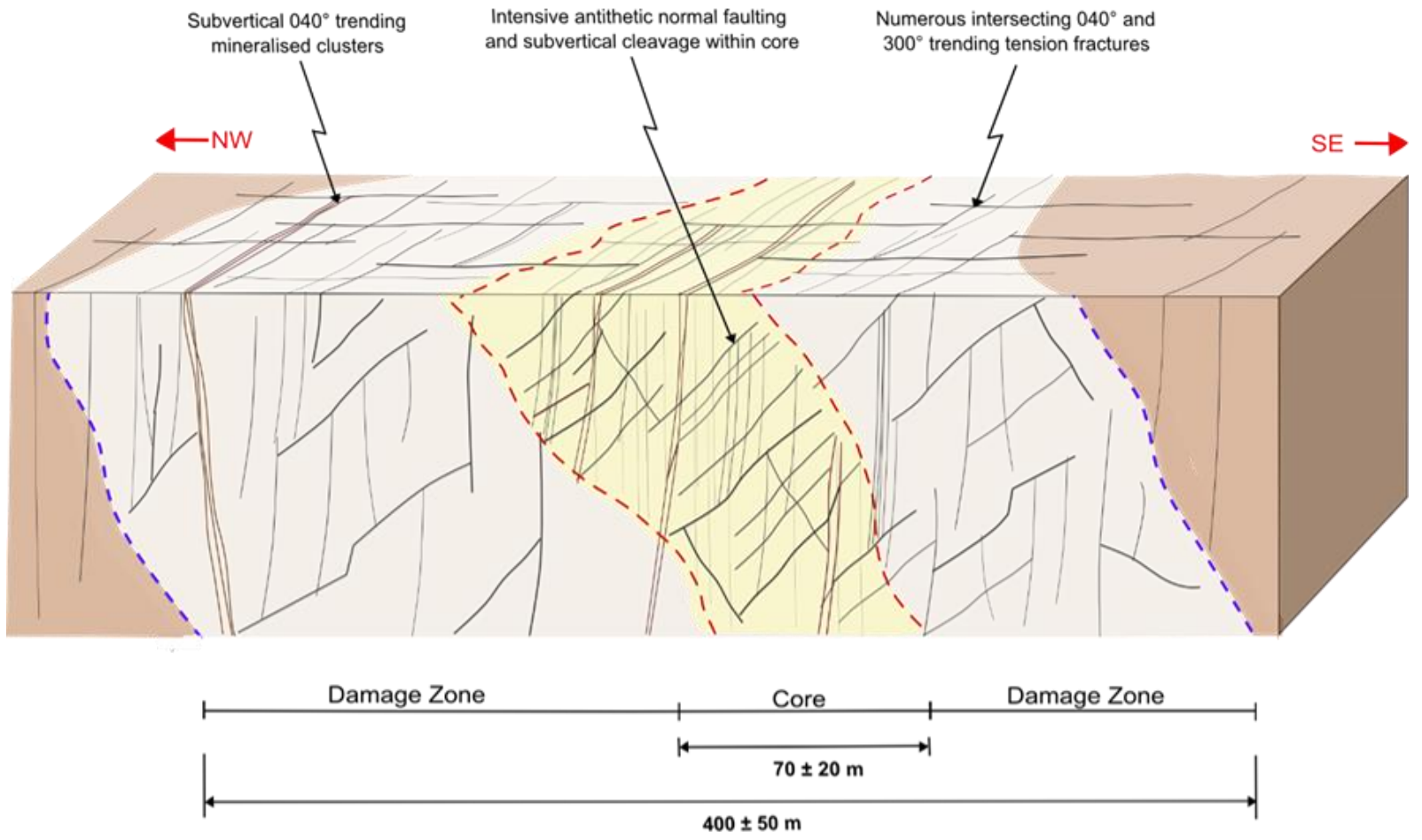

Maiden Rock Fault Summary

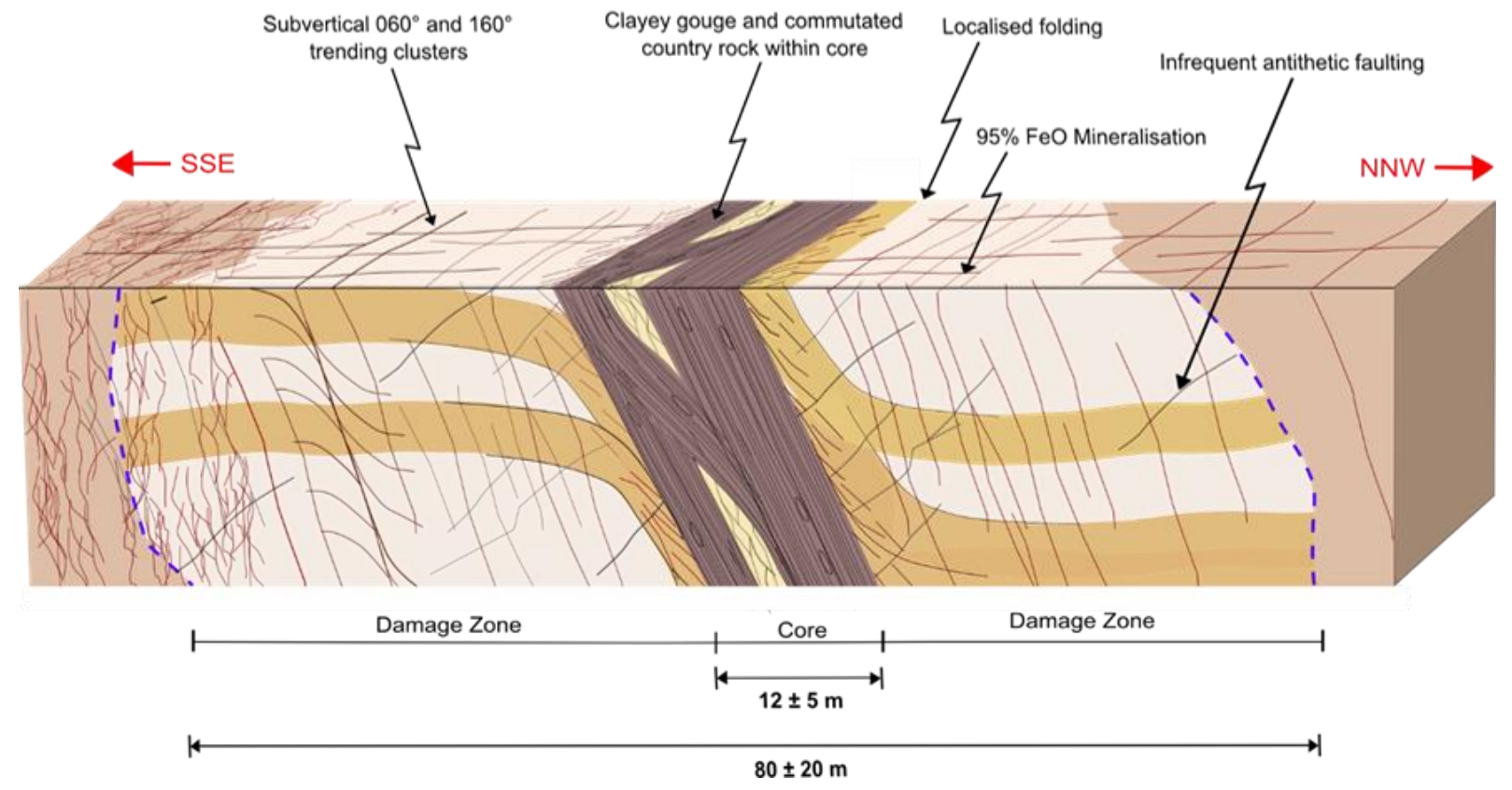

Figure 6: Schematic overview of the Dura Den and Maiden Rock Faults, showing the relative widths of the core and damage zone and fracture trends within these zones. The Dura Den fault can be characterised as having widespread fracturing in minimal mineralisation. Dominant subvertical fracturing suggests that along-fault fluid flow within the DDF would be enhanced, whilst normal faulting would accommodate across-fault flow. The Maiden Rock Fault is almost entirely mineralised with extensive clayey gouge in the fault core, rendering the fault a regional barrier to groundwater flow. The two faults can thus be respectively categorised as a 'distributed conduit' and 'localised barrier' (Caine, et al., 1996). 


\subsection{Discrete Fracture Network (DFN) Modelling}

Mapped fracture data and circular scan line data was assimilated and analysed using Move software to identify clustering in fracture orientation for the DDF site. Eight fracture clusters were identified using the K-mean clustering algorithm (Figure 7), a method described in MacQueen (1967). Observed field fracture characteristics (Table 1) were then allocated to each cluster by orientation using the CW data. DFNs were modelled to represent the entire fault as a geo-mechanical facies of homogenous permeability (McDermott, et al., 2006a), as fracture data was insufficiently high resolution to distinguish the core and damage zone permeability with statistical certainty.

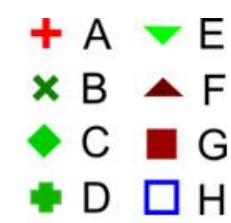

Figure 7: Stereoplot showing poles to fracture planes, $n=487.8$ digitally identified fracture clusters are shown, corresponding to fracture types A-F in Table 2. Inset key shows symbols for each cluster.

Table 2 shows the attributes specific to the eight identified fracture clusters, with fracture type determined from fracture displacement. Given that the site is located within The Scottish Midland valley, a failed rift system, most fracture types are associated with extensional deformation. Regional fracture patterns were inferred through the correlation of data between the two study sites. Quantitative fracture data was derived by grouping data points encompassed by the plotted areas shown in Figure 8 . Once the data had been grouped, the statistical mean and standard error for these groups was calculated for intensity, length and aperture. Subsequently, a DFN was created for the DDF site using the eight identified fracture clusters. The DFN modelling process requires setting five parameters to define each fracture set modelled. These are intensity, orientation, length, aperture and aspect ratio. The first four 


\begin{tabular}{|c|c|c|c|c|c|c|}
\hline & Fracture Type & $\begin{array}{c}\text { Cluster } \\
\text { Orientation }\end{array}$ & $\begin{array}{c}\text { Fisher } \\
\text { Dispersion }\end{array}$ & $\begin{array}{c}\text { Mean Intensity } \\
\qquad\left(\text { Fracs } / \mathbf{m}^{3}\right)\end{array}$ & $\begin{array}{c}\text { Mean } \\
\text { Length } \\
(\mathbf{m})\end{array}$ & $\begin{array}{c}\text { Mean Aperture } \\
\text { (mm) }\end{array}$ \\
\hline $\mathbf{A}$ & Extensional (Mode I) & $86 / 195$ & 14.7 & $2.1 \pm 0.3$ & $3.3 \pm 0.1$ & $0.6 \pm 0.5$ \\
\hline B & $\begin{array}{l}\text { Extensional (Mode I) also } \\
\text { observed at MRF site } \\
\text { suggesting regional fracturing }\end{array}$ & $87 / 50$ & 34.9 & $3.5 \pm 0.2$ & $6.5 \pm 0.6$ & $1.4 \pm 0.9$ \\
\hline $\mathbf{C}$ & Extensional (Mode I) & $83 / 081$ & 20.8 & $1.9 \pm 0.4$ & $5.7 \pm 0.1$ & $0.7 \pm 0.7$ \\
\hline $\mathbf{D}$ & $\begin{array}{l}\text { Shear (Mode II) fractures } \\
\text { associated with antithetic } \\
\text { normal faulting }\end{array}$ & $37 / 298$ & 21.6 & $0.7 \pm 0.3$ & $2.7 \pm 0.6$ & $1.5 \pm 0.4$ \\
\hline $\mathbf{E}$ & Extensional (Mode I) & $74 / 280$ & 27.0 & $1.7 \pm 0.3$ & $6.7 \pm 0.6$ & $1.8 \pm 1.4$ \\
\hline $\mathbf{F}$ & $\begin{array}{l}\text { Extensional (Mode I) also } \\
\text { observed at MRF site } \\
\text { suggesting regional fracturing }\end{array}$ & $89 / 309$ & 38.6 & $1.9 \pm 0.2$ & $4.6 \pm 0.3$ & $1.3 \pm 1.0$ \\
\hline $\mathbf{G}$ & Extensional (Mode I) & $84 / 340$ & 29.4 & $1.5 \pm 0.3$ & $3.6 \pm 0.2$ & $1.3 \pm 0.6$ \\
\hline $\mathbf{H}$ & $\begin{array}{l}\text { Extensional (Mode I) possible } \\
\text { sub-horizontal exhumation } \\
\text { related fracturing }\end{array}$ & $17 / 107$ & 15.4 & $1.4 \pm 0.6$ & $5.4 \pm 0.3$ & $0.8 \pm 0.4$ \\
\hline
\end{tabular}

Table 2: A summary of the characteristics of the identified fracture clusters coupled with descriptive and quantitative data derived from Circle Window sampling. This is subsequently used to define fracture sets within numerical simulations. Fisher Dispersion (K) quantifies the dispersion of fracture data around each modelled cluster. Uncertainty given by standard deviation from mean.

200 To review the validity of the fracture model, Figure 8 presents the generated DFN model for comparison with the collated field data (Figure 4A). The distribution and orientation of the fracture sets in the DFN is observed to be qualitatively representative of the field data. However, an apparent difference in the relative intensity of fracture clusters exists between Figure 4A and Figure 8 (intensity is colour mapped). It should be highlighted that the intensity displayed in Figure 4A represents the frequency a fracture orientation has been mapped across the whole area, and is therefore subject to significant observation biases, as discussed previously. The relative intensities shown in Figure 8, however, are a result of 

intensity of fracture sets in the field.

209

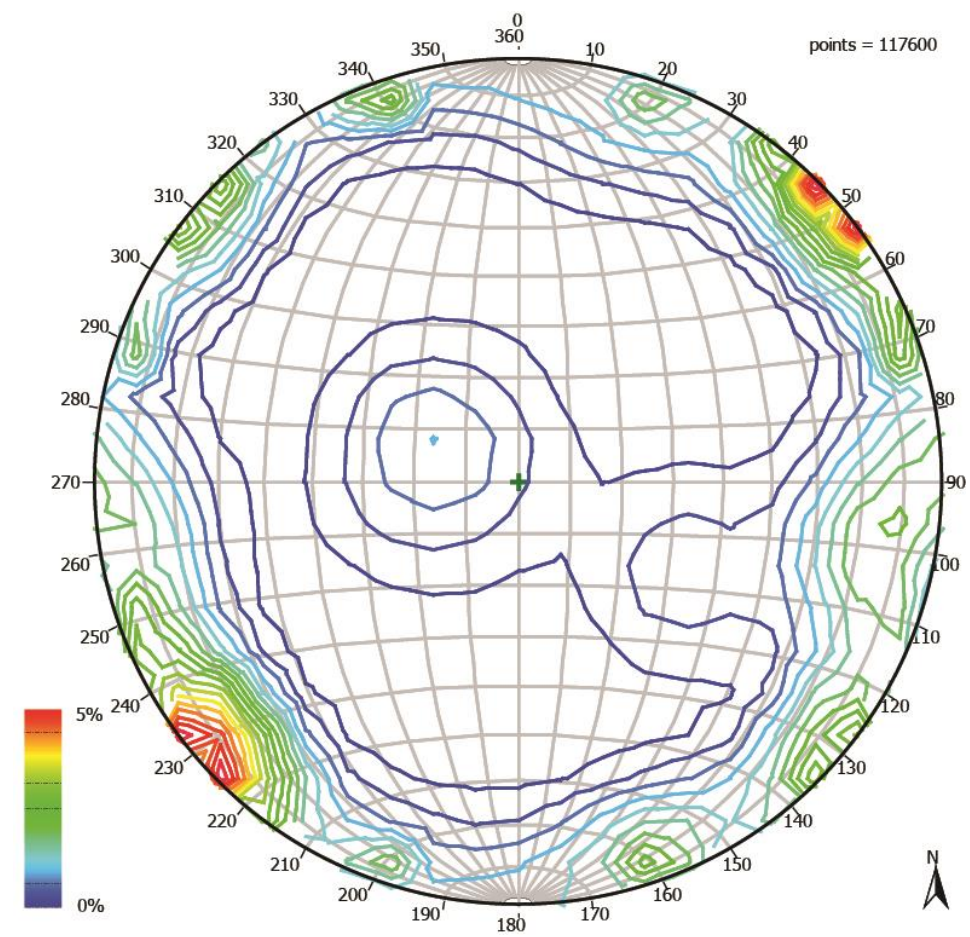

Figure 8: Contoured stereoplots of Generated mean scenario DFN for the Dura Den Fault. Contour colour indicates density of data, in terms of percentage of total data points falling within a given $1 \%$ area of the plot with red indicating greatest $(5 \%)$ and blue the lowest $(0.4 \%)$. Contour interval $=0.4 \%$.

\subsection{Fracture Network Permeability Modelling}

Quantitative analysis of bulk fracture permeability was conducted using the Move fracture modelling module, which generates stochastic Discrete Fracture Networks (DFN) from measured fracture data. The output permeability tensor associated with each DFN is expressed as a $3 \mathrm{x} 3$ matrix, $\mathrm{k}_{\mathrm{xx}}, \mathrm{k}_{\mathrm{yy}}$ and $\mathrm{k}_{\mathrm{zz}}$, expressed in Darcys, providing quantitative data to represent the fault zone in regional modelling. For continuity of presentation with the regional modelling, we have converted permeabilities to $\mathrm{m}^{2}$.

The method of calculating the permeability tensor follows Oda (1985), deriving an equivalent porosity for a DFN within a sample volume. For a grid cell, a fracture tensor is calculated by adding individual fractures weighted by area and transmissivity. The calculation for each DFN is based on Darcy's Law and laminar flow between surfaces (Midland Valley, 2015). The resulting tensor is expressed as:

$$
k_{i j}^{(c)}=\lambda\left(P_{k k} \delta_{i j}-P_{i j}\right)
$$

where $k_{i j}{ }^{(c)}$ is the equivalent permeability tensor representing a fracture system $P_{k k}$, and $P_{i j}$ is the 'crack tensor', a symmetric tensor relating to fracture geometry, $\lambda$ is a dimensionless constant relating to flow velocity, $\delta_{i j}$ is Kronecker delta. $P_{k k}$ is expressed by three geometric component values. 


$$
P_{k k}=P_{11}+P_{22}+P_{33}
$$

227 Discrete fracture clusters derived from field data were applied to a sample volume of $8000 \mathrm{~m}^{3}$ (Figure

228 9). The size of the sample volume was chosen to be greater than the maximum fracture length but also 229 to be small enough to optimise the processing speed of the model. Three models (minimum, mean, 230 maximum) were produced from the statistical distribution of recorded fracture data around the mean 231 values of fracture intensity, length, and aperture; the minimum permeability scenario was defined as 232 minus one standard deviation, and the maximum plus one standard deviation (Table 2). The mean was 233 used to provide a best estimate of the bulk fracture properties and the statistical distribution of fracture 234 properties was then used to establish the sensitivity of bulk permeability values to fracture properties.

235 Figure 9 shows the hydraulic parameters calculated for the three modelling scenarios for the DDF.

237 It should be highlighted that fracture properties, in particular fracture length, are described by scale 238 dependant variables. However, meaningfully estimating power law and fractal characteristics from 239 field data is non-trivial (Bonnet, et al., 2001). A key issue is the statistical complexity extrapolating single dimensional fracture data to three dimensions, requiring very large datasets. Therefore the scaling properties of the given fracture data has not been addressed. Due to the near-complete mineralisation, fracture systems within the MRF damage zone were not modelled.

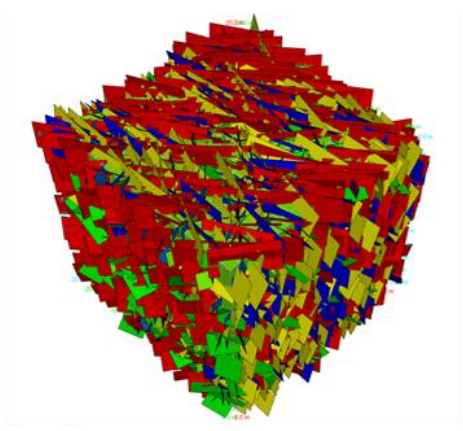

Minimum k Bulk k: $1.52 \times 10^{-11} \pm 7.7 \times 10^{-12} \mathrm{~m}^{2}$ Porosity: $7 \pm 3 \%$

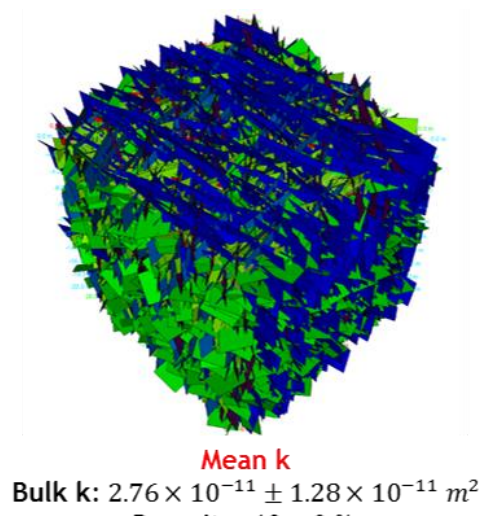

Porosity: $18 \pm 8 \%$

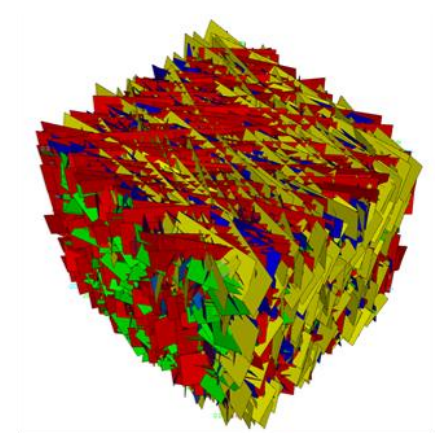

Maximum k

Bulk k: $1.09 \times 10^{-10} \pm 5.72 \times 10^{-11} \mathrm{~m}^{2}$ Porosity: $36 \pm 18 \%$

$$
\left[\begin{array}{ccc}
3.17 \times 10^{-12} & 0 & 0 \\
0 & 2.58 \times 10^{-12} & 0 \\
0 & 0 & 4.92 \times 10^{-12}
\end{array}\right] \quad\left[\begin{array}{ccc}
1.51 \times 10^{-11} & 0 & 0 \\
0 & 1.74 \times 11 & 0 \\
0 & 0 & 2.71 \times 10^{-11}
\end{array}\right] \quad\left[\begin{array}{ccc}
5.66 \times 10^{-11} & 0 \\
0 & 7.28 \times 10^{-11} & 0 \\
0 & 0 & 1.08 \times 10^{-10}
\end{array}\right]
$$

Figure 9: Results from fracture permeability modelling for the Dura Den Fault. Screenshots of the 20m x 20m x 20m sample volumes within which fracture clusters where generated. For the minimum, mean and maximum permeability scenarios corresponding increasing fracture density and length can be observed to standard aquifer rock types. Within the DFN model coordinate system, the $\mathrm{x}$ - dimension corresponds to NW - SE. Permeability values apply at surface exposure.

249 Figure 9 shows that, within each permeability scenario, permeability tensors are on the same order of magnitude between cartesian axes. Between the maximum and minimum permeability scenarios, the 
251 bulk FZ permeability varies by two orders of magnitude, suggesting significant uncertainty on the mean 252 bulk permeability. Extrapolating DFN permeabilities derived from surface fracture data to 253 geomechanical facies at depth is a challenge, especially with no down-hole data for the area to validate 254 the process. Due to the low confining stresses at the surface, measured apertures are likely to be larger 255 than in the subsurface where confining pressures act to close fractures. In addition, fracture intensity 256 may be lower in the subsurface as exhumation jointing and fractures may not be present. It is therefore reasonable to expect that permeabilities at depth will be less than those estimated from the surface fracture data.

The calculated permeability values (Figure 9) are up to three orders of magnitude higher than the permeability values for the unfaulted strata (Table 5), a disparity in excess of those found in analogous studies of faulted sandstone aquifers (Evans, et al., 1997; Fraser Harris, et al., 2015). To address this and the expectation of fewer, tighter fractures at depth, the fracture permeability data has been adjusted for depth-related controls on permeability (Table 3).

Pratt et al (1977) present an in-situ experimental dataset quantifying the permeability reduction of jointing with applied normal stresses. Assuming the normal stress applied to fractures within the DDF is equivalent to hydrostatic pressure, a depth permeability reduction factor has been calculated from Pratt et. al.'s dataset. This was calculated for three depths within the Dura Den fault, referred to as upper, middle and lower.

\begin{tabular}{|l|r|rrr|}
\hline DDF Section & \multicolumn{1}{|c|}{ Surface } & \multicolumn{1}{c|}{ Upper } & \multicolumn{1}{c|}{ Middle } & \multicolumn{1}{c|}{ Lower } \\
\hline Depth $(\mathbf{m})$ & 0 & 425 & 1000 & 5800 \\
\hline Hydrostatic Pressure $(\mathbf{M P a})$ & 0.1 & 4.2 & 9.8 & 58.2 \\
\hline Permeability Reduction $\left(\mathbf{m}^{2}\right)$ & 0 & $2.10 \times 10^{-02}$ & $8.82 \times 10^{-03}$ & $1.40 \times 10^{-03}$ \\
\hline Min KXX $\left(\mathbf{m}^{2}\right)$ & $3.17 \times 10^{-12}$ & $6.64 \times 10^{-14}$ & $2.8 \times 10^{-14}$ & $4.45 \times 10^{-15}$ \\
Min KYY & $2.58 \times 10^{-12}$ & $5.39 \times 10^{-14}$ & $2.27 \times 10^{-14}$ & $3.61 \times 10^{-15}$ \\
Min KZZ & $4.92 \times 10^{-12}$ & $1.03 \times 10^{-13}$ & $4.34 \times 10^{-14}$ & $6.9 \times 10^{-15}$ \\
\hline Mean KXX $\left(\mathbf{m}^{2}\right)$ & $1.51 \times 10^{-11}$ & $3.17 \times 10^{-13}$ & $1.34 \times 10^{-13}$ & $2.12 \times 10^{-14}$ \\
Mean KYY & $1.74 \times 10^{-11}$ & $3.63 \times 10^{-13}$ & $1.53 \times 10^{-13}$ & $2.43 \times 10^{-14}$ \\
Mean KZZ & $2.71 \times 10^{-11}$ & $5.68 \times 10^{-13}$ & $2.39 \times 10^{-13}$ & $3.8 \times 10^{-14}$ \\
\hline Max KXX $\left(\mathbf{m}^{2}\right)$ & $5.66 \times 10^{-11}$ & $1.18 \times 10^{-12}$ & $4.98 \times 10^{-13}$ & $7.93 \times 10^{-14}$ \\
Max KYY & $7.28 \times 10^{-11}$ & $1.53 \times 10^{-12}$ & $6.42 \times 10^{-13}$ & $1.02 \times 10^{-13}$ \\
Max KZZ & $1.08 \times 10^{-10}$ & $2.26 \times 10^{-12}$ & $9.53 \times 10^{-13}$ & $1.51 \times 10^{-13}$ \\
\hline
\end{tabular}

Table 3: Effect of hydrostatic pressure on bulk fault fracture permeability for three different depth sections within the DDF, based on joint permeability data sourced from Pratt et. al. (1977).

272 In addition to depth-related controls, (Cherubini, et al., 2014) observe that an important control on the 273 hydraulic properties of fractures is their orientation relative to the present-day in-situ stress field. The current stress field in Scotland is described as near east-west extension (Baptie, 2010) with a NNW 
trending maximum compressive stress (Heidbach, et al., 2008). This compressive stress would most likely act to reduce the aperture of subvertical, WNW trending fractures. However, as there are no current data quantifying the magnitude of these regional stresses their influence on fracture permeability has not been addressed in this study.

\subsection{Conceptual Model of the Strathden Group Aquifers}

The model constitutes a cuboidal volume of $13 \mathrm{~km}$ x $10 \mathrm{~km}$ x $5.8 \mathrm{~km}$, with the model $\mathrm{x}$-axis trending at $310^{\circ}$, orthogonal to the trend of the DDF (Figure 10). This encompasses most large-scale structural heterogeneity around the Guardbridge site.

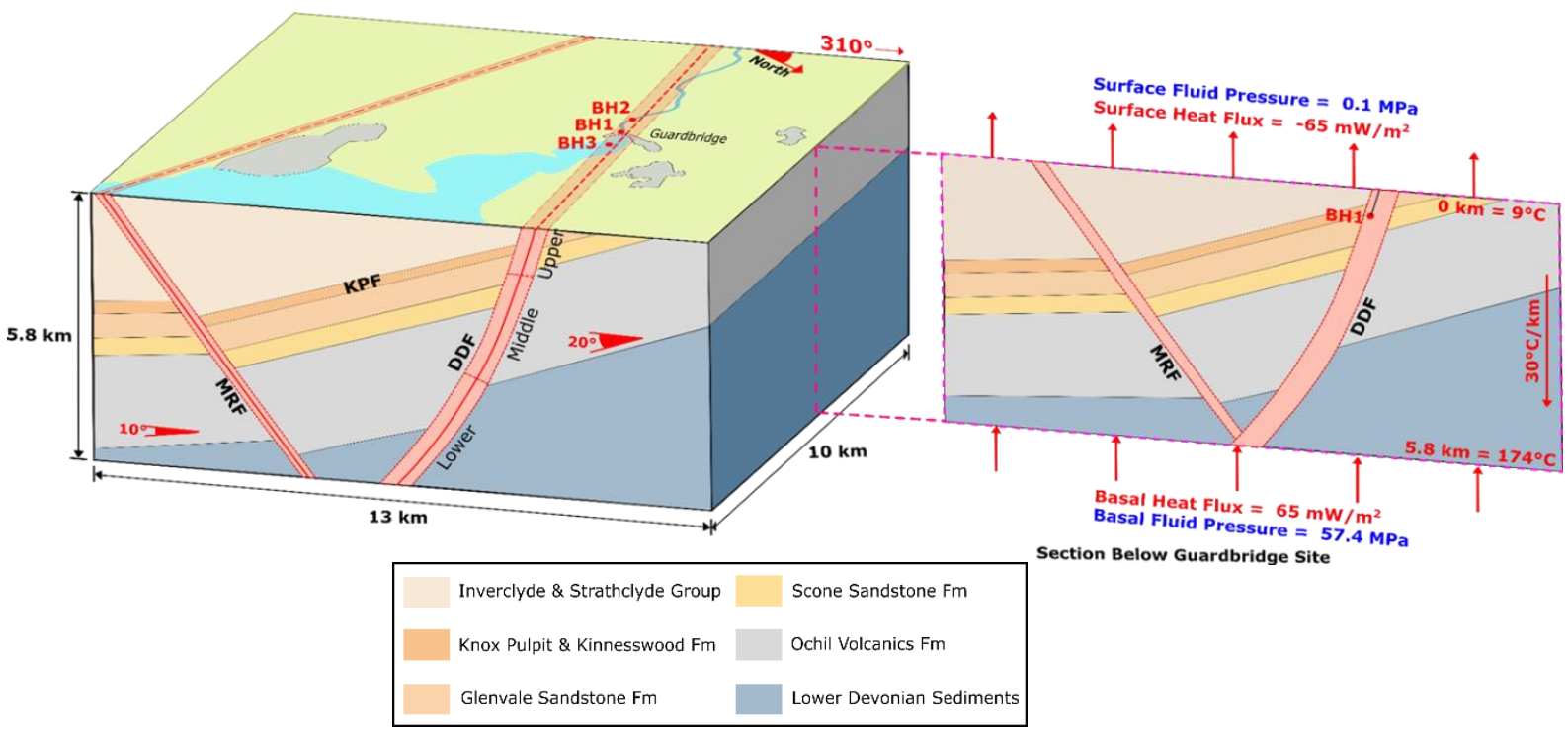

Figure 10: Conceptual model of the Guardbridge Site, showing the 3D geometry of the Dura Den Fault, the Maiden Rock Fault and the surrounding strata. Groundwater and heat boundary conditions and borehole locations are also shown on the 2D projected section. The East and West faces of the model have a thermal boundary condition that reflects the geothermal gradient. The projected section represents the subsurface geometry below the Guardbridge site.

The Dura Den and Maiden Rock faults are represented as shear zones of finite thickness formed of discrete intersecting fractures (Talwani, et al., 1999; McDermott, et al., 2006a). The permeability architecture of the DDF and MRF can thus be defined by discrete hydraulic boundaries and unique material properties (McDermott, et al., 2006a). The FDZ and undeformed strata are therefore distinguished in terms of geo-mechanical facies (Figure 2), conforming to relative deformation intensity.

A model for the geometry of the DDF is described in Robinson et al (2016), based on previous structural models (McCoss, 1987). Around the south dipping DDF, gently SE dipping strata show approximately 700m normal displacement (Robinson, et al., 2016). The north-dipping MRF has been represented with laterally varying displacement, with c. 200m of slip at its easternmost extent reducing to zero displacement in the west. 
An overview of the hydrology of the Strathden aquifer system is presented by Gauss \& Ó Dochartaigh et al (2000). The authors describe groundwater recharge as being sourced from the western and northern extent of the Eden catchment. This creates a trend in groundwater flow from the topographic highs in these areas, towards the River Eden in the valley (Gauss \& Ó Dochartaigh 2000, Robinson et al 2016). The near surface unsaturated zone ranges from $0 \mathrm{~m}$ up to $40 \mathrm{~m}$ in depth (BGS, 1986) which is far below the resolution of this large-scale regional model. Therefore, our conceptual model assumes full groundwater saturation but includes an estimate of the groundwater level from the elevation of streams in the model area, assuming effluent river courses. A constant Neumann rainfall boundary condition was applied to the model surface, with previous publications finding this to be $700 \mathrm{~mm}$ per year with an assumed 50\% recharge (BGS, 1986).

310 The undamaged aquifer permeability and porosity values were sourced from previous studies (Ó 311 Dochartaigh, 2004; Robinson, et al., 2016) (Table 4). Although the Midland Valley is a site of 312 Carboniferous intrusive and volcanic activity, the influence in our model area is localised to the SW 313 of the domain and cross-cutting relationships show the DDF and MRF to be younger. Therefore, for 314 simplicity, these have been omitted from our regional scale model. The fluid specific heat capacity $315\left(4.18 \times 10^{3} \mathrm{~J} / \mathrm{g} \cdot{ }^{\circ} \mathrm{C}\right)$, and specific heat conductivity $\left(0.6 \mathrm{~W} \cdot \mathrm{m}^{-1} \cdot{ }^{\circ} \mathrm{C}^{-1}\right)$ have been assumed to be constant 316 at all depths. All rock material groups were given a uniform thermal conductivity of $3.0 \mathrm{~W} \cdot \mathrm{m}^{-1} \cdot{ }^{\circ} \mathrm{C}^{-1}$.

317 Heat dispersion was set to $50 \mathrm{~m}: 1 / 4$ the smallest mesh length. Coupling between the hydraulic and 318 thermal processes is through temperature $\left(T\left({ }^{\circ} \mathrm{C}\right)\right)$ dependent fluid density $\left(\rho\left(\mathrm{kg} / \mathrm{m}^{3}\right)\right)$ and viscosity 319 ( $\mu$ (Pa.s)) functions that lead to a temperature dependent hydraulic conductivity for a given unit:

$$
\mu(T)=0.00229-0.00101 * \log _{10}(T)
$$

\begin{tabular}{|c|c|c|c|c|c|}
\hline \multicolumn{6}{|c|}{$\rho(T)=1000 *(1-0.0004 *(T))$} \\
\hline Unit & $\begin{array}{l}\text { Permeability } \\
\left(\mathrm{m}^{2}\right)\end{array}$ & Porosity $(\%)$ & Storage (-) & Tor & $\begin{array}{r}3 s^{3} \mathrm{Z}^{2} \\
323\end{array}$ \\
\hline Inverclyde Group ${ }^{\text {a }}$ & $1.55 \times 10^{-15}$ & 11 & $1.0 \times 10^{-8}$ & 1.0 & 324 \\
\hline $\begin{array}{l}\text { Knox Pulpit } \\
\text { Formation }^{\text {a }}\end{array}$ & $\begin{array}{l}1.55 \times 10^{-15} \text { to } \\
1.55 \times 10^{-14}\end{array}$ & 14 & $1.0 \times 10^{-8}$ & 1.0 & $\begin{array}{l}325 \\
326\end{array}$ \\
\hline Glenvale Sandstone $^{a}$ & $1.55 \times 10^{-15}$ & 9 & $1.0 \times 10^{-8}$ & 1.0 & \\
\hline Scone Sandstone ${ }^{a}$ & $1.62 \times 10^{-15}$ & 9 & $1.0 \times 10^{-8}$ & 1.0 & 329 \\
\hline Ochil Volcanics $^{a}$ & $1.00 \times 10^{-16}$ & 5 & $1.0 \times 10^{-8}$ & 1.0 & 330 \\
\hline Arbuthnott Group ${ }^{b}$ & $1.00 \times 10^{-17}$ & 2 & $1.0 \times 10^{-9}$ & 1.0 & $\begin{array}{r}331 \\
332\end{array}$ \\
\hline
\end{tabular}

Table 4: Overview of the hydraulic properties of modelled undamaged aquifers. The hydrogeological properties presented show an order of magnitude of uncertainty in Robinson et al. (2016), however only the uncertainty in the KPF permeability is addressed in this study (Ó Dochartaigh, 2004; Robinson, et al., 2016). ${ }^{a}$ hydraulic properties derived directly from previous studies , (Ó Dochartaigh, 2004; Robinson, et al., 2016) ${ }^{\mathrm{b}}$ hydraulic properties estimated for sandstones buried to $4 \mathrm{~km}$ depth . 
338 The geometry and boundary conditions for the conceptual model are summarised in

339 Figure 10. The pressure boundary at the base is defined by the hydrostatic pressure from mean sea

340 level to the base of the model taking into account the effect of variable fluid density, and the surface

341 fluid pressure is defined as atmospheric pressure. A $65 \mathrm{~mW} / \mathrm{m}^{2}$ regional heat flux (Busby, 2010) is

342 applied as a Neumann boundary condition to the base of the model and a corresponding heat flux

343 allowing the heat to escape the model is applied to every surface node. A thermal gradient of 30

$344{ }^{\circ} \mathrm{C} / \mathrm{km}$, sourced from regional borehole data (Gillespie, et al., 2013), is imposed as an initial condition

345 and as boundary conditions on the East and West vertical faces of the model.

346 3. Numerical Modelling of Groundwater and Heat Flow using OpenGeoSys

347 The model examines two main controls on the sustainability of groundwater extraction over a 50-

348 year period- the average down-hole temperature change over the extraction period, and the amount

349 of hydraulic drawdown within the aquifer system. It is normal for geothermal resources to change

350 temperature over the duration of their usage, but extraction becomes impractical if the fluid

351 temperature decreases to unusable temperatures. Similarly, excessive drawdown resulting from

352 groundwater extraction can be detrimental to a geothermal scheme, resulting in exhaustion of the

353 aquifer system. We therefore conduct a sensitivity analysis to explore the impact of the uncertainty

354 of the permeability of the KPF, determine the impact of the range of expected withdrawal rates, and

355 examine the possibility of using multiple boreholes to extract the fluid and the impact of reinjection

356 of fluid to limit drawdown.

357 Numerical modelling is conducted with the versatile open source finite element code OpenGeoSys

358 (Kolditz et al 2012) by solving the governing equations for hydraulic flow and heat transport over

359 the finite element mesh shown in Figure 11. The unstructured mesh constituted 51,707 nodes and

360273,662 elements and was generated using the open source code Gmsh (Geuzaine \& Remacle, 2009)

361 (Figure 11). Node spacing around the faults and the Strathden Group and DDF damage zone was set

362 to $200 \mathrm{~m}$, whilst node spacing towards the model boundaries where detailed observation of fluid and

363 heat flow was not necessary was $300 \mathrm{~m}$. Hydraulic flow is described by Darcy's law and sequentially

364 coupled to the heat transport equation through density and viscosity dependent fluid properties.

365 Further information on this methodology in OpenGeoSys can be found in Fraser Harris et al (2015). 


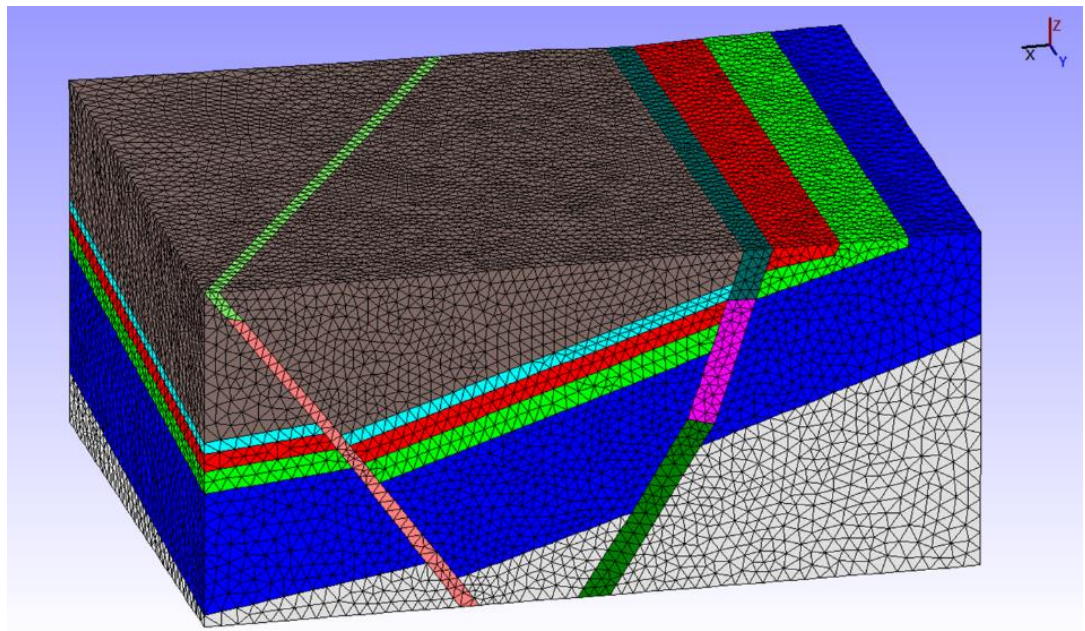

Figure 11:3D finite element mesh used in the coupled thermo-hydraulic simulation.

\subsection{Steady-State regional groundwater flow}

369 An initial steady-state model was run for a 1-year period to calculate the fluid pressure and temperature 370 throughout the domain, before using the results of this as initial conditions for the transient solution of coupled thermal-hydraulic behaviour. The lack of data at depth requires a qualitative assessment of the 372 steady state model suitability before moving on to a transient solution.

373 A near surface flow vector plot from the steady-state model is shown in Figure 12. In accordance with 374 Gauss \& Ó Dochartaigh et al (2000), the model creates fluid flow conditions from the topographic highs 375 in the SW and NW corners of the model, resulting in regional groundwater flow towards to the River 376 Eden in the valley. A portion of flow occurs longitudinally down the valley, but this is less significant 377 in comparison to flow towards the valley. Qualitatively, this provides a basis from which to investigate 378 the impact of geothermal extraction. 


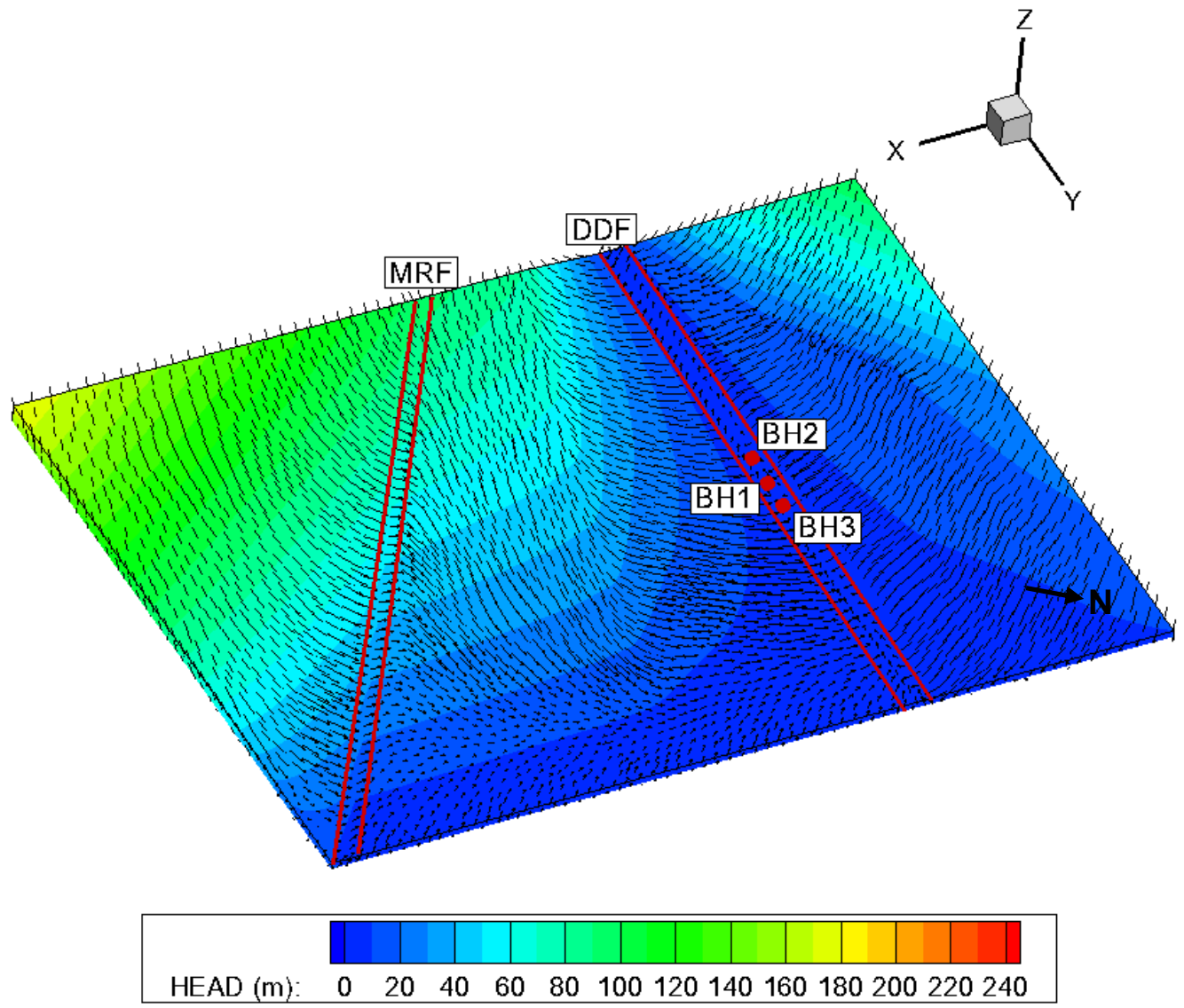

Figure 12: Uniform length vector plot of the steady-state model, section from $100 \mathrm{~m}$ depth to the model surface showing the general patterns of groundwater flow. X-axis is parallel to NW/SE direction and the Y-axis to NE/SW. The locations of the boreholes are shown, with Guardbridge situated above BH1.

384 In the following analysis, head values, changes in head, and changes in temperature are presented on two orthogonal cross-sections through the model. One cross-section is parallel to the strike of the Dura

386 Den Fault zone, and the other cuts through the location of the central borehole. The location of these cross-sections is shown in Figure 13. 


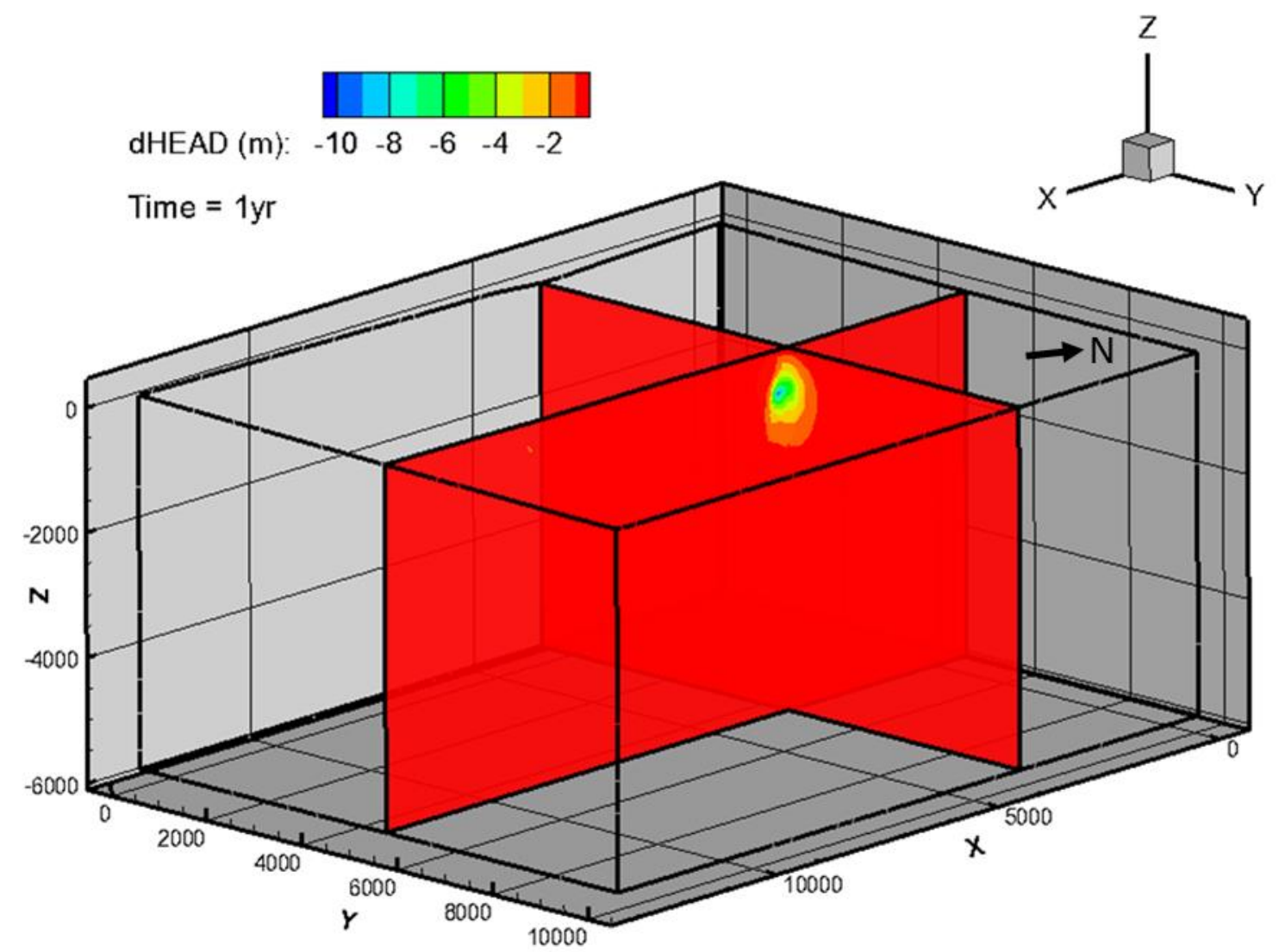

Figure 13: Locations of the two orthogonal slices used to present the model results in the analysis of different extraction rates and well configurations

391 The elevated permeability of the Dura Den Fault zone is highlighted by the cross-sectional vector plot

392 in Figure 14 where the largest flow vectors are situated within the upper sections of this geomechanical

393 facies. This highlights that flow through the fault damage zone is preferential to through the lower

394 permeability matrix. In contrast, the impermeable nature of the Maiden Rock Fault is evident, causing significant deviation of flow vectors. Also evident in the vector plot is the contribution of Strathden group Sandstones, acting to recharge the fault zone up-dip. This is accentuated in the maximum KPF permeability scenario. However, it is still clear the DDF damage zone has the largest potential for fluid flow. 

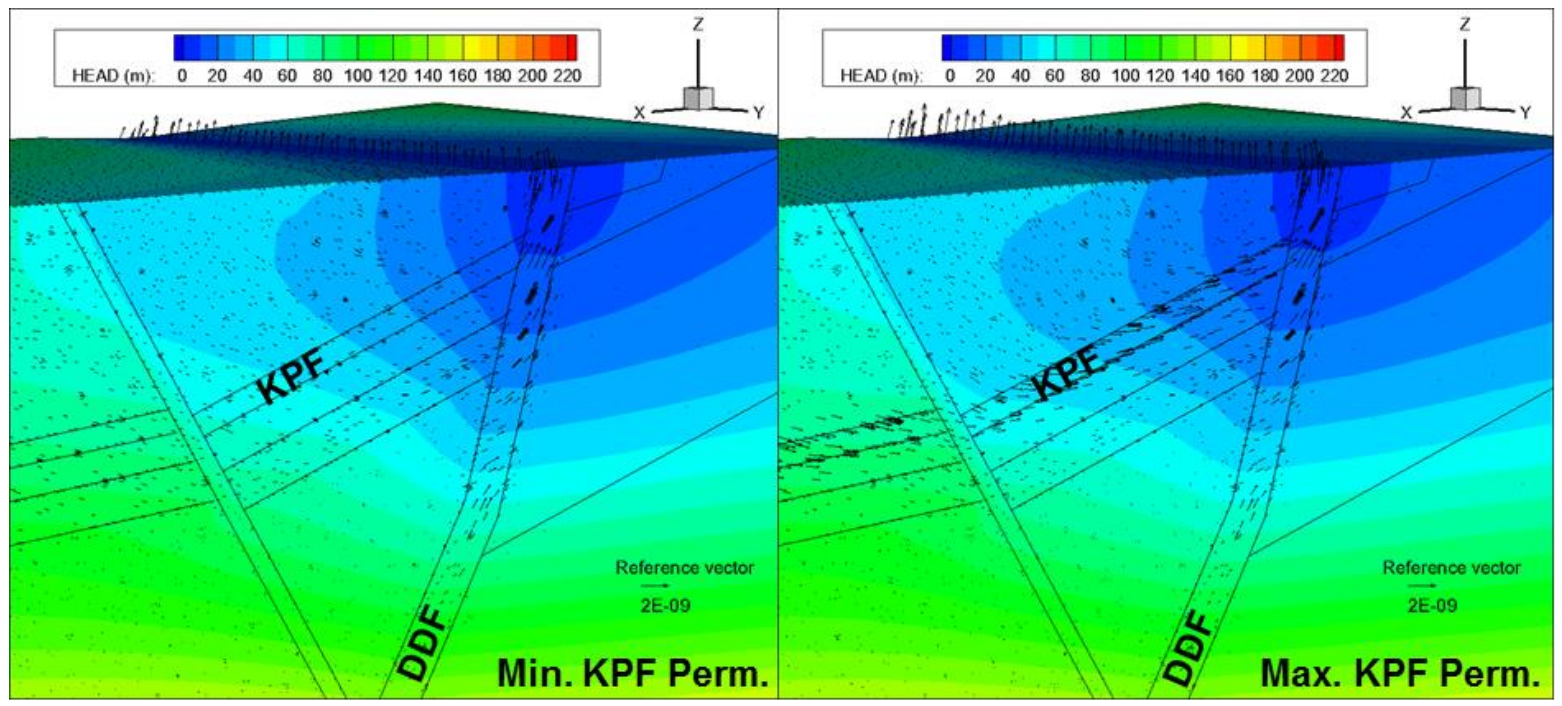

Figure 14: Cross sectional vector plot along the line shown perpendicular to the DDF in Figure 13, with vector length proportional to flow velocity. The steady-state model shows general trends in groundwater flow for minimum and maximum KPF permeability. X-axis is parallel to NW/SE direction and the Y-axis to NE/SW. The line of section for Figure 13 is indicated in Figure 12.

\subsection{Transient modelling scenarios- Geothermal heat extraction}

A further 50-year period was then modelled for transient flow scenarios to investigate heat production and associated hydraulic and thermal drawdown with extraction. The minimum permeability values for the DDF and KPF model with extraction rate of $15 \mathrm{Ls}^{-1}$ represents a reference model from which the following different scenarios were tested:

- Literature ranges of KPF permeability

- Single well extraction at $5 \mathrm{Ls}^{-1}, 15 \mathrm{Ls}^{-1}$, and $20 \mathrm{Ls}^{-1}$

- Multi-well extraction from three boreholes at $5 \mathrm{Ls}^{-1}$

- Multi-well extraction and injection scenario (central injection with two lateral extraction wells and central extraction with two lateral injection wells)

Boundary conditions were kept the same as for the steady-state model, with source terms included for the extraction wells. The three boreholes were located with bottomhole depths of $691 \mathrm{~m}$ below mean average sea level. One borehole (BH1) is positioned directly below the Guardbridge site and two others are located approximately 500m west (BH2) and east (BH3) of $\mathrm{BH} 1$ along the strike of the DDF. These are thus positioned within the DDF damage zone at the depth of the KPF formation, in line with Robinson et al. (2016), to simulate geothermal energy extraction from the fracture permeability of the target horizon associated within the DDF. Each borehole has an open length of c. $300 \mathrm{~m}$ with an elevation change of 50-100 m. This leads to a steeper borehole than the angle of dip of the KPF, as outlined in Robinson et al (2016), however this is a function of the locations of the nodes in the model mesh. The dominance of the sub-vertical fracture sets in the field data suggests a deviated well 
perpendicular to the strike of the fault damage zone would have the highest potential to access multiple

426 flowing fractures.

427 The total district heat demand for the settlements of Guardbridge, Leuchars and Balmullo was 428 calculated by Robinson et al (2016) to be $40000 \mathrm{MWh}$. The energy output of a geothermal system to 429 supply this demand is calculated using the Specific Heat equation:

$$
Q=c m \Delta T
$$

431 Where $\mathrm{Q}$ is the heat energy produced per second ( $\mathrm{J}$ ), $\mathrm{m}$ is the mass of water extracted per second (e.g. $43215 \mathrm{~kg}), \mathrm{c}$ is the specific heat capacity of water $\left(4.18 \mathrm{~J} / \mathrm{g} \cdot{ }^{\circ} \mathrm{C}\right)$, and $\Delta \mathrm{T}$ is the difference between 433 atmospheric $\left(\right.$ c. $9{ }^{\circ} \mathrm{C}$ ) and groundwater temperature. Converting the heat demand to $\mathrm{W}(\mathrm{J} / \mathrm{s})$ by first 434 converting MWh to MW (by dividing by 3600 seconds), and then to $\mathrm{W}$ by dividing by $1 \times 10^{6}$, enables 435 an estimate of the extraction rate required to satisfy the heat demand. Assuming the heat extracted from 436 the geothermal scheme provides a $\Delta T$ of $20{ }^{\circ} \mathrm{C}$, a somewhat unrealistic extraction rate of $133 \mathrm{Ls}^{-1}$ 437 would be required to fully supply the heat demand.

438 Robinson et al (2016) suggested that extraction rates of 5 to $20 \mathrm{Ls}^{-1}$ were more compatible with the 439 expected permeability at the target depth based on levels of hydraulic drawdown and shallow borehole 440 yields, and concluded that the geothermal project would need to be supplemented by an alternative heat 441 source to meet local demand. Initial simulation results for an extraction rate of $133 \mathrm{Ls}^{-1}$ suggested a 442 hydraulic drawdown in excess of $300 \mathrm{~m}$, which we have deemed to be too great for a sustainable 443 geothermal project. We therefore simulate a range of extraction rates from 5 to $20 \mathrm{Ls}^{-1}$, corresponding 444 to extraction rates proposed by Robinson et al (2016), in a number of scenarios based on different well 445 configurations. 
Results from the reference model of the minimum permeability scenario for the KPF and the DDF with an extraction rate of $15 \mathrm{Ls}^{-1}$ from the hypothetical borehole situated closest to Guardbridge are presented in Figure 15. These two cross-sections are perpendicular to the DDF (Figure 15A), and parallel to the strike of the DDF (Figure 15B), as shown in Figure 13. The distribution of the change in head shows that most of the water supplying the well is provided by the elevated permeability of the FDZ, with more significant supply from the FDZ than from the unfaulted units. A small proportion of groundwater is supplied from the KPF and the other sediments in the Strathden Group, but the majority is sourced from the DDF. Very little fluid is sourced from the Ochil Volcanics Formation to the NE of the DDF.

Figure 15: Simulation results from the reference model. A) shows the change in head on a cross-section perpendicular to the

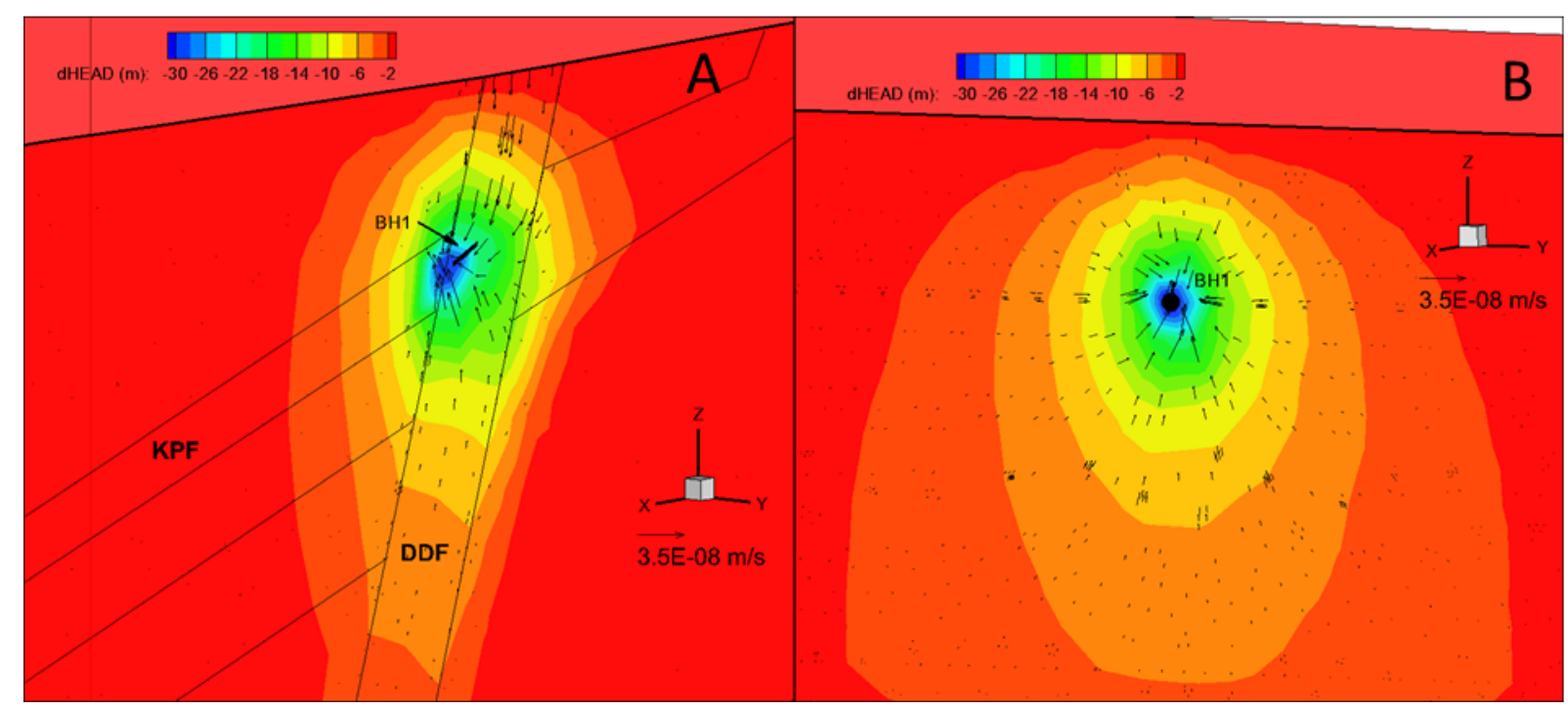
strik)

A plot of head and temperature at both the top and base of the borehole is shown in Figure 16. This indicates hydraulic drawdown is greater at the base of the borehole because of the lower permeability of the fault damage zone at greater depths. The temperature at the base of the borehole rises as warmer water is drawn up the fault zone, and the temperature at the top of the borehole decreases because cooler water is drawn down from the fault zone above. The mixing of these waters leads to a stable production temperature over the 50-year extraction period but a hydraulic drawdown of $27.65 \mathrm{~m}$. Hydraulic drawdown reaches a quasi-steady state after approximately 10 years, after which head continues to reduce at a slow rate. Under these extraction rates and estimated permeabilities, this suggests the water budget is the key control over the viability of the resource. It should also be noted that due to a lack of downhole stress measurements, we do not simulate the thermal-mechanical processes that influence longevity of the thermal resource in a fracture-dominated HSA. Nevertheless, our simulations indicate the thermal drawdown is negligible over a 50-year period of sustained pumping. 


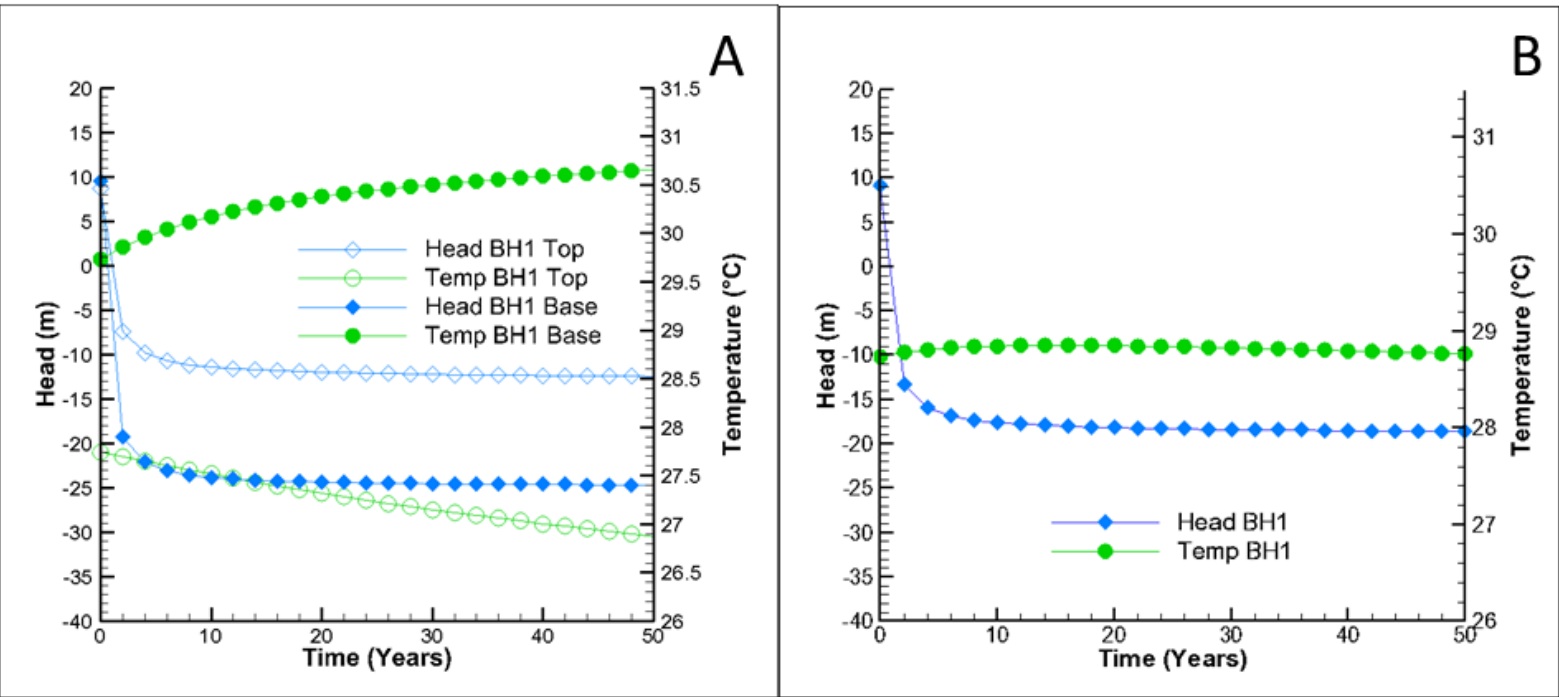

Figure 16: Head and temperature plots at the top and bottom of the borehole in the reference model (A), and averaged temperature and head for the borehole in the reference model $(\mathbf{B})$.

\subsection{KPF permeability}

Literature permeability ranges for the KPF (Table 4) were investigated by adjusting the permeability

from the reference case (minimum permeability) in line with the maximum value in the literature (Robinson et al 2016). All other modelling parameters were kept constant. Figure 17 shows the effect of the different KPF permeability under extraction at $15 \mathrm{Ls}^{-1}$.
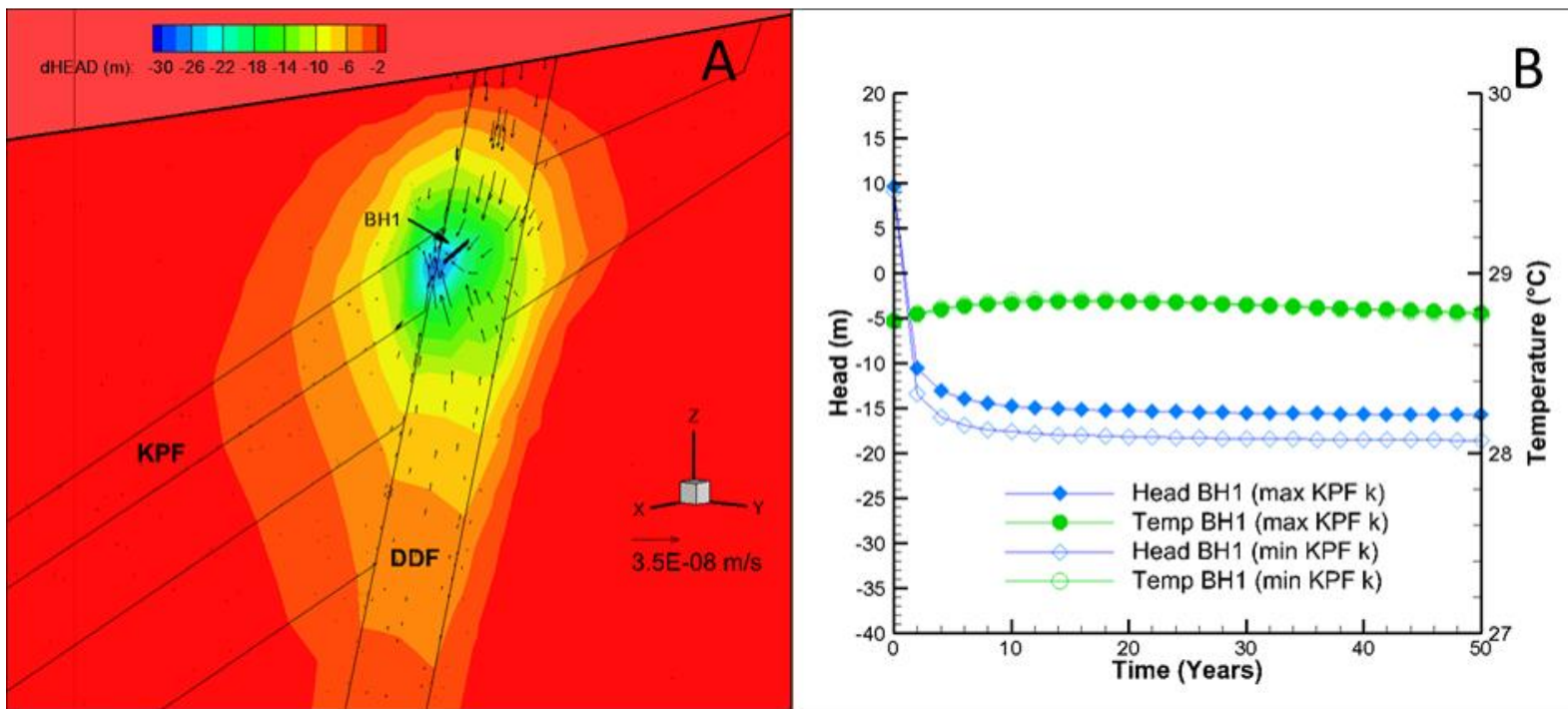

Figure 17: A cross-section through BH1 perpendicular to the DDF showing the change in head in the maximum KPF permeability scenario (A), and a comparison of the thermal and hydraulic drawdown in the minimum and maximum KPF scenarios $(\mathbf{B})$

In the maximum KPF scenario a larger proportion of water is drawn from the unfaulted sandstone units resulting in a reduction in hydraulic drawdown in comparison to the reference model, though most fluid is still supplied by the fault zone (Figure 17). In Figure 17B it can be observed that the 25.35 m hydraulic 
drawdown is lower than in the minimum KPF permeability scenario, but the temperature difference is negligible.

\subsection{Influence of extraction rate}

Extraction rates were varied from the reference case to encompass the maximum $\left(20 \mathrm{Ls}^{-1}\right)$ and minimum $\left(5 \mathrm{Ls}^{-1}\right)$ extraction rates considered to be economic in the Robinson et al (2016) report. All other model parameters were kept constant.

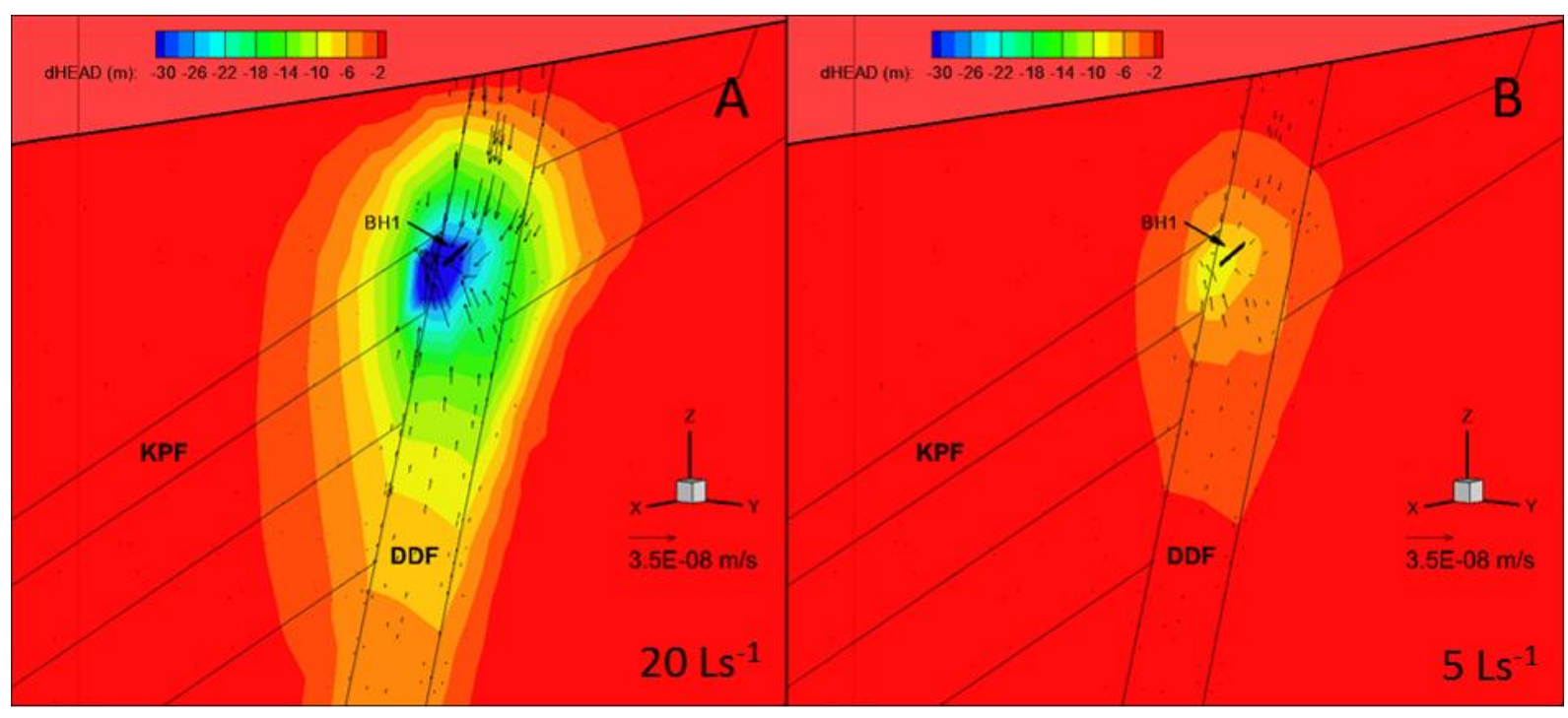

Figure 18: A cross-section through BH1 perpendicular to the DDF comparing the change in head with different extraction rates $\left(\mathrm{A}=20 \mathrm{Ls}^{-1}, \mathrm{~B}=5 \mathrm{Ls}^{-1}\right)$

Figure 18 shows that, as would be expected, a $20 \mathrm{Ls}^{-1}$ extraction rate significantly increases the magnitude and extent of hydraulic drawdown within the aquifer system compared to $5 \mathrm{Ls}^{-1}$. At lower flow rates, the distribution of the change in head indicates fluid is still predominantly supplied by the fault zone but, as the drawdown is less, the permeability of the DDF is sufficient to supply the well without excessive drawdown. Thermal drawdown is shown in Figure 19 along with a comparison with the change in head and temperature for the different extraction rates. Thermal drawdown is shown to be localised to the elevated permeability of the DDF with a greater change in fluid temperatures in the fault zone above the borehole. Figure 19B shows that hydraulic drawdown is $36.94 \mathrm{~m}$ under $20 \mathrm{Ls}^{-1}$ extraction rates but just 9.14 m under $5 \mathrm{Ls}^{-1}$ extraction rates. Consequently, there is a noticeable thermal drawdown at $20 \mathrm{Ls}^{-1}$ after 50 years because the extraction rate exceeds thermal recharge from deeper waters. The lower extraction however, indicates a slight temperature rise after 50 years of pumping, suggesting that the difference in temperature in fluid drawn up from depth is greater than for the cooler water drawn down from above the borehole. These lower extraction rates suggest favourable conditions from a hydrogeological point of view but reduce the amount of heat power generated by the geothermal plant. To address this, multiple extraction wells were also considered. 


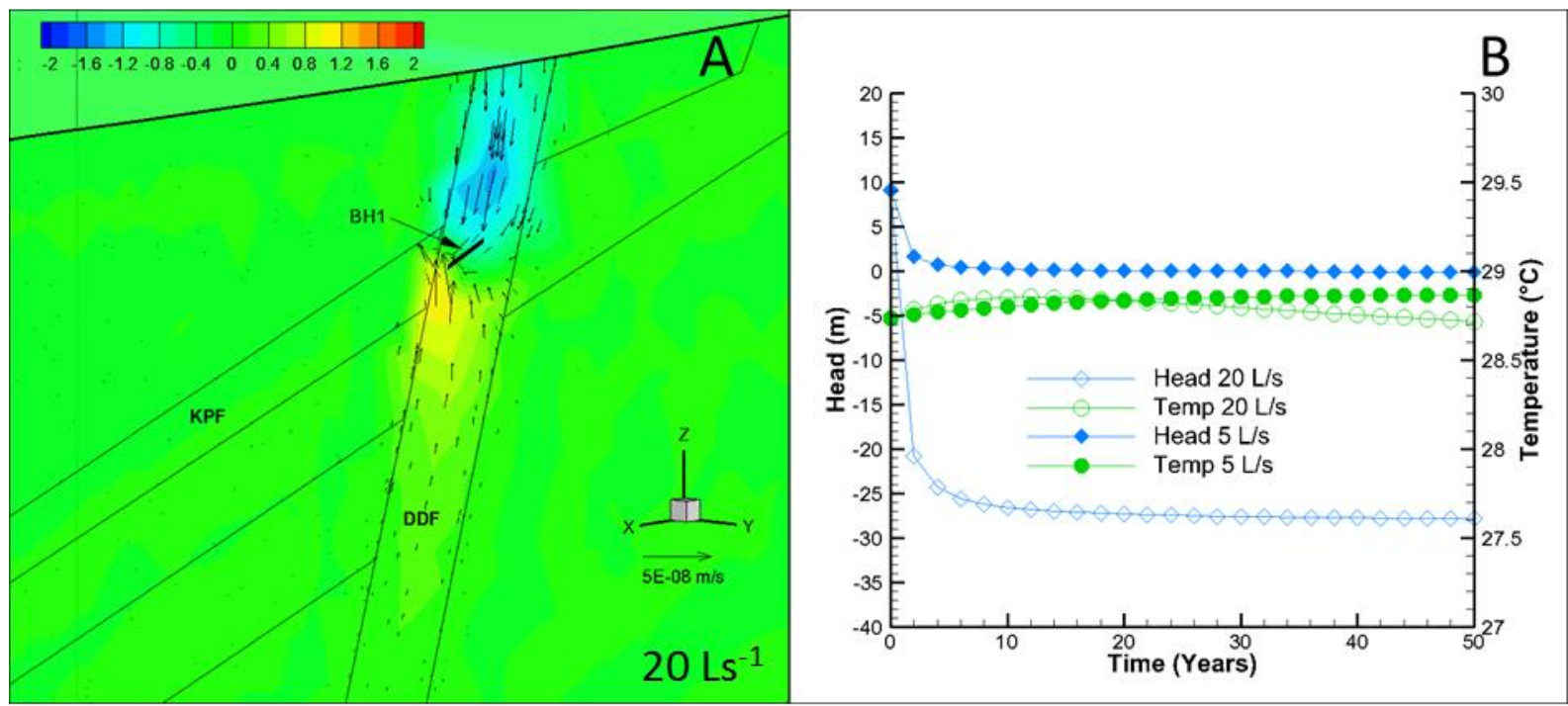

513 Figure 19: A cross-section through the BH 1 perpendicular to the DDF showing the change in temperature under $20 \mathrm{Ls}^{-1}$ extraction rates (A), and a comparison between the head and temperature at 5 and $20 \mathrm{Ls}^{-1}$ extraction rates

\subsection{Multiple extraction wells}

516 A multi-well scenario was considered with three boreholes separated by approximately $500 \mathrm{~m}$ along 517 the DDF, as shown in Figure 12. A total extraction rate of $15 \mathrm{Ls}^{-1}$ was considered to compare against 518 the reference model. Figure 20 shows the results of the simulation after 50 years of pumping, using a section parallel to the DDF to show the hydraulic and thermal drawdown at each well. Extraction is distributed over a larger region of the damage zone, reducing hydraulic drawdown and exploiting fracture permeability. The distributed effects of extraction are observable, where drawdown is $12.50 \mathrm{~m}$ from all three BHs combined, compared to $27.64 \mathrm{~m}$ in Figure 16. Hydraulic drawdown is thus is more than halved in comparison to a single well, with the distribution of the pumping across three extraction wells and the thermal drawdown is just $0.02{ }^{\circ} \mathrm{C}$ (Figure 21). Flow vectors also indicate more significant

525 lateral recharge from within the DDF fault zone with extraction from multiple BH's. This suggests that 526 a multiple extraction well configurations could be employed to mitigate the effects of hydraulic drawdown. 


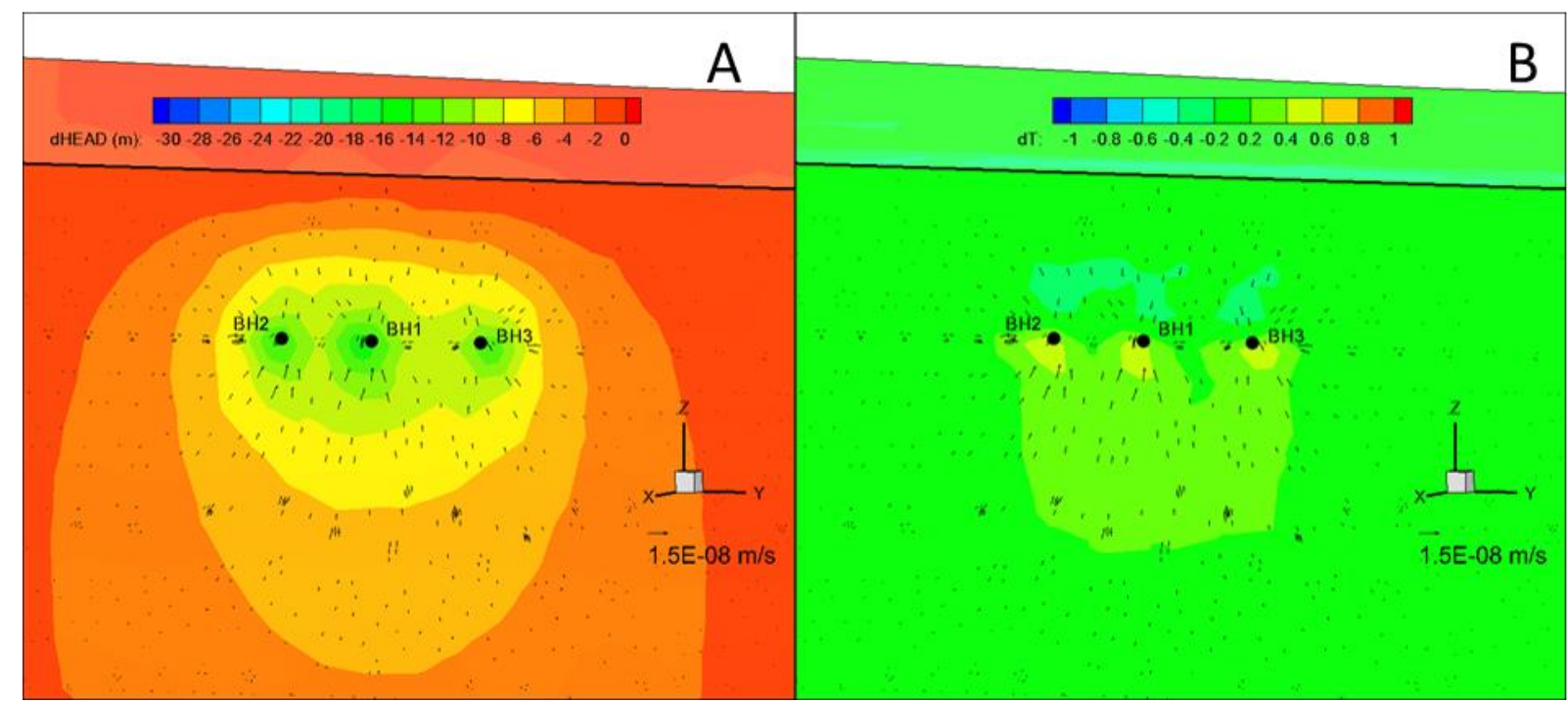

530 Figure 20: Cross-sections through the borehole locations parallel to the DDF showing the hydraulic (A) and thermal (B)

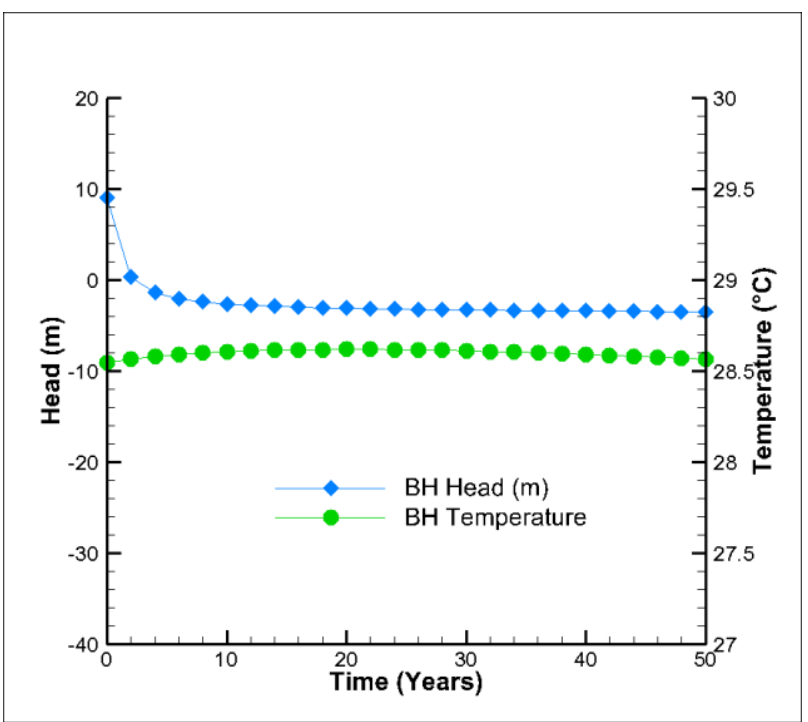

Figure 21: Average head and temperature for all three boreholes during the multi-well extraction scenario of a combined 15 $\mathrm{Ls}^{-1}$.

\subsection{Extraction and reinjection scenarios}

537 One method to mitigate the hydraulic drawdown in a producing aquifer is to reinject the produced fluid.

538 Here we investigated the potential impacts of reinjection in two scenarios - reinjection through a central 539 borehole with extraction from the two lateral boreholes, and reinjection at the two lateral boreholes with 540 extraction from the central borehole. In both cases the total water produced from the extraction well(s) 541 was $15 \mathrm{Ls}^{-1}$. The injection borehole was assigned a temperature boundary condition of $9{ }^{\circ} \mathrm{C}$ to simulate 542 the conditions in Equation 5. Temperature rise of this fluid as it is pumped down the well is not considered in this model because a temperature of $9{ }^{\circ} \mathrm{C}$ represents a worst-case scenario for thermal 
breakthrough in this TH model. Simulations were run for 200 years to investigate thermal drawdown and potential thermal breakthrough.

546 The results indicate that, at these extraction rates, the permeability of the DDF is sufficiently low and 547 the boreholes spaced far enough apart for thermal drawdown of the resource due to reinjected fluid to 548 be insignificant even after 200 years (Figure 22). Figure 23 shows the heads and temperatures for each 549 borehole. Hydraulic drawdown in the dual extraction model is markedly reduced in comparison to the 550 reference model ( $8.54 \mathrm{~m}$ vs $27.64 \mathrm{~m}$ ), and also lower than the three extraction well scenario despite the 551 increased extraction rate $(8.54 \mathrm{~m}$ vs $12.36 \mathrm{~m})$. This suggests that re-injection has a small mitigating effect on hydraulic drawdown. In comparison, the single extraction well model has a drawdown of $22.49 \mathrm{~m}$, which is slightly reduced from the reference model, but nearly 3 times larger than the dual extraction model.

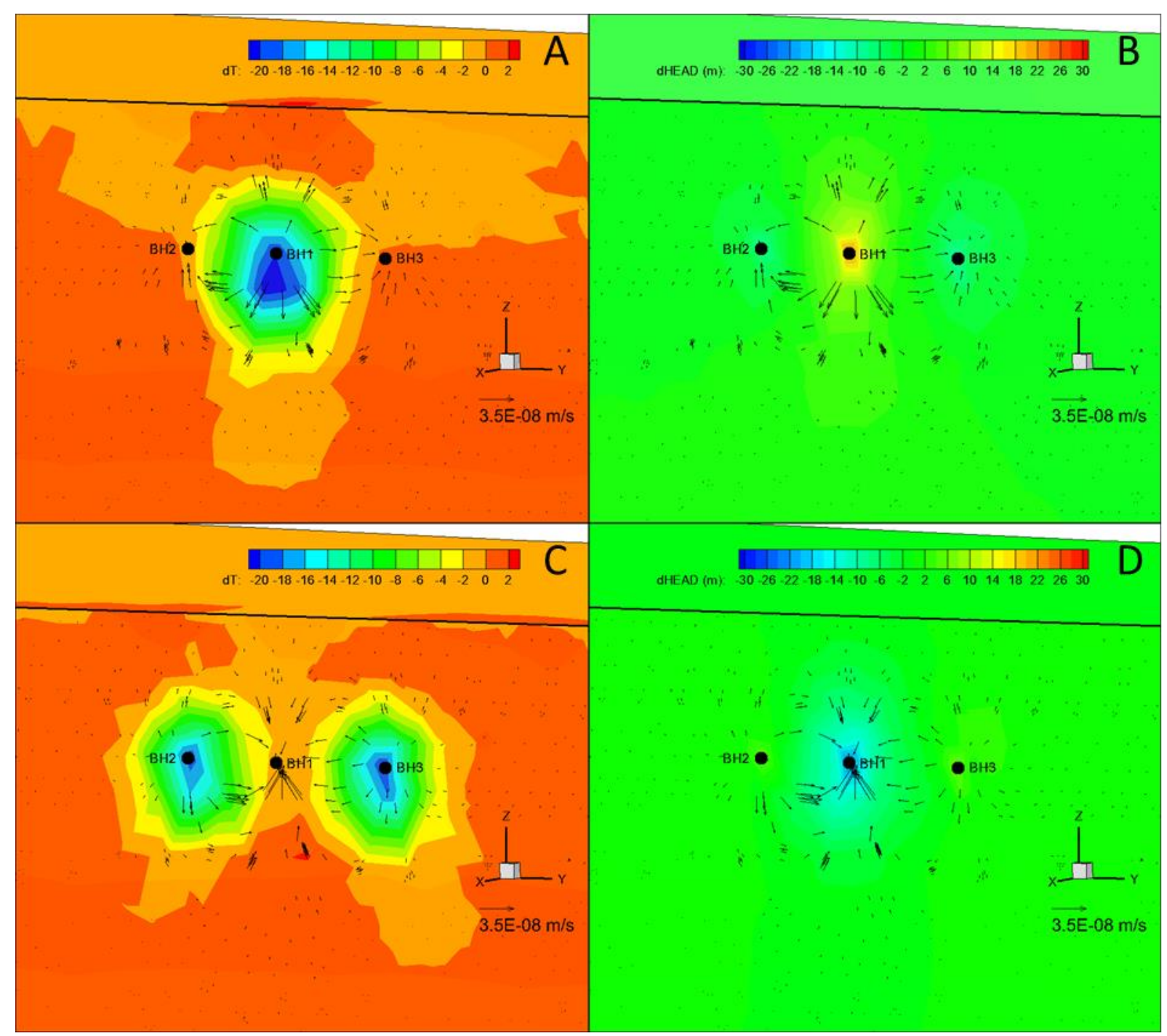

Figure 22: Cross-sections parallel to the DDF showing the change in head and temperature during the two 


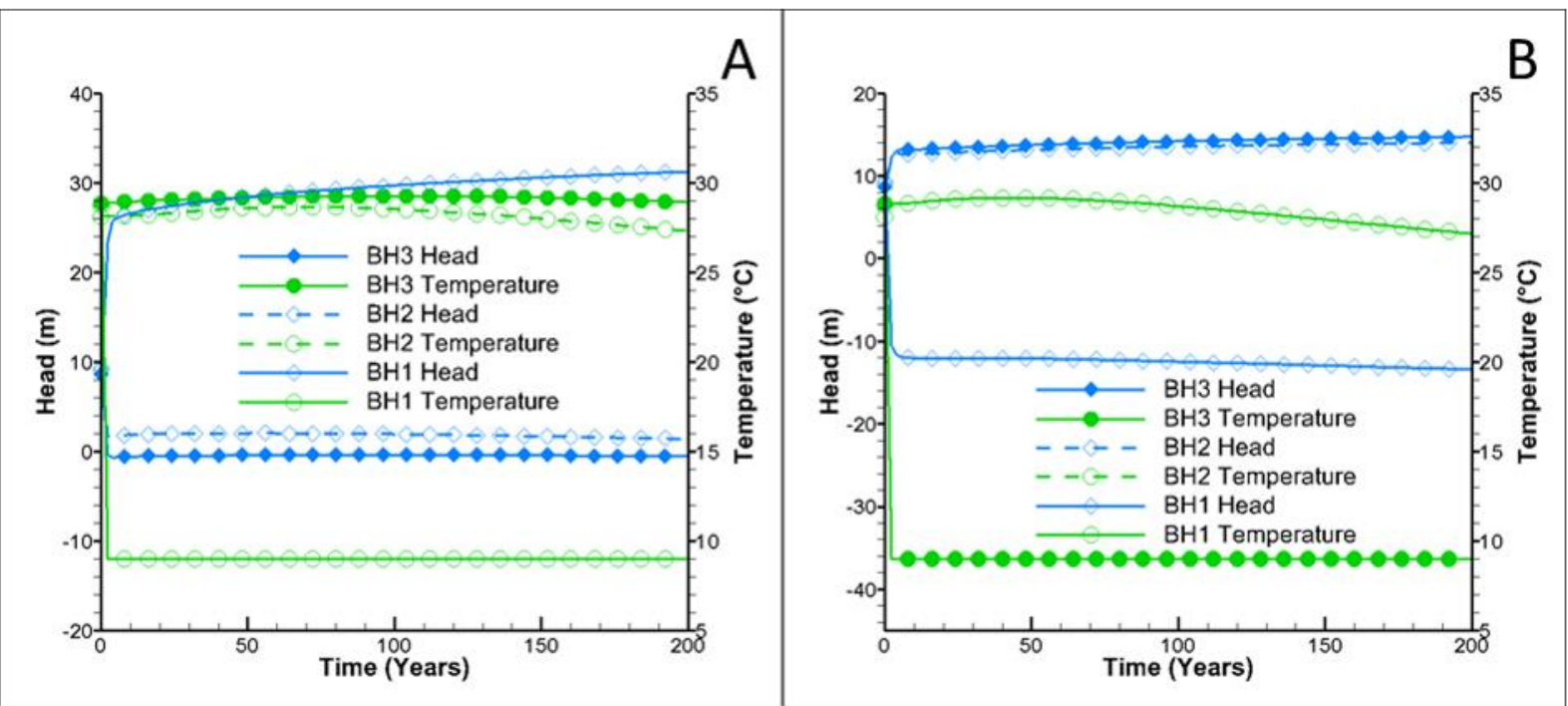

Figure 23: Plots of mean head and temperature in each borehole in the extraction/reinjection scenarios at $15 \mathrm{Ls}^{-1} . \mathbf{A}=\operatorname{single}$ injection (BH1), dual extraction (BH2 \& $\mathrm{BH} 3$ ), and $\mathbf{B}=$ single extraction (BH1), dual injection (BH2 \& $\mathrm{BH} 3$ ).

\subsection{Summary of Regional Hydrogeological Modelling}

It is apparent from both the steady state and transient modelling scenarios that the DDF damage zone has a significant influence on regional groundwater flow patterns below Guardbridge. The increased permeability and resulting flow anisotropy appears to dictate subvertical groundwater movement. In all extraction scenarios, flow vectors and temperature change shows that boreholes are almost entirely supplied by fluid from the fault damage zone. It could thus be inferred that the modelled fault damage zone permeability is required to enable sustainable geothermal production, with fluid flow within fault zone significantly exceeding contributions from the Knox Pulpit Formation. This supports Robinson et al (2016), whose numerical model indicated that intergranular permeability was not sufficient to sustain fluid extraction.

Between all extraction scenarios, after 50 years the mean $\mathrm{BH}$ temperature change with extraction does not exceed $0.5{ }^{\circ} \mathrm{C}$, which, relative to the c. $20^{\circ} \mathrm{C}$ temperature change supplying the district heating system, is negligible. The key controls, therefore, on the viability of an extraction scheme are the potential flow rate and the magnitude of the drawdown within the aquifer system. The greatest drawdown is observed in single well scenarios (c $.40 \mathrm{~m}$ at $\left.20 \mathrm{Ls}^{-1}\right)$. Whilst this in small in comparison to the depth of the well $(691 \mathrm{~m})$, this could affect surface hydrology local to Guardbridge.

Multi-well extraction and extraction/reinjection scenarios go some way to mitigating the hydraulic drawdown at the extraction wells without negatively affecting the thermal productivity of the resource (assuming uniform fault damage zone properties and not taking into account thermal-mechanical processes). With the development of multiple boreholes, acquirement of multiple drilling sites or directional drilling would need to be considered. The calculated permeability values indicate that situating the well(s) within the fault damage zone provides optimal hydraulic characteristics, however it is worth considering that groundwater extraction from fault zones comes with risks and logistical 
585 challenges (Yerkes \& Castle, 1976; Holzer, et al., 1979). The precise position and orientation of the 586 DDF damage zone also remains uncertain at depth (Robinson, et al., 2016), therefore further work 587 would be necessary to constrain structural uncertainties.

588

\section{Conclusions}

Extensive field fracture mapping and circle window sampling of two intersecting regional scale faults and their associated damage zones was conducted to determine fault zone architecture and assess their role in subsurface fluid flow at a potential Hot Sedimentary Aquifer geothermal prospect in East-Central Scotland. We concluded that the Dura Den Fault represents a distributed conduit for groundwater flow whereas the Maiden Rock Fault is a localised inhibitor of groundwater flow. Using the conceptual models developed from this fieldwork and the fracture data collected, Discrete Fracture Network modelling was carried out to obtain equivalent porous medium properties for the damage zone of the Dura Den Fault. This was then applied in the first 3-D coupled thermo-hydraulic numerical model of the potential site. The calculated DFN permeabilities were adjusted for depth in the model in three zones (shallow, medium, and deep) based on the estimated confining pressure at these depths.

A number of modelling scenarios were considered to investigate the controlling factors on geothermal production, determine appropriate potential extraction rates, and analyse multi-well extraction/injection configurations. Results suggest that fluid is sourced predominantly from the Dura Den Fault zone, and that mixing of cool water from above and warm water from below results in a stable production temperature in excess of 50 years. Hydraulic drawdown is therefore the key controlling factor that may determine the viability of geothermal production at this site. Multi-well configurations with both extraction and injection enable this hydraulic drawdown to be mitigated by accessing a larger volume of rock and distributing the hydraulic load. A configuration of two extraction wells and a single central injection well provides the best possible mitigation of hydraulic drawdown. However, this obviously comes with logistical and technical challenges associated with siting three wells in a fault damage zone. Modelling indicates that this site has the potential to provide sustainable geothermal heat for c. $11 \%$ of the local heat demand calculated by Robinson et. al. (2016), corresponding to approximately 230 properties for over 50 years.

\section{Acknowledgements}

GJ was supported by EPSRC Grant EP/P026214/1. The authors would like to thank Midland Valley for the use of the Move modelling suite. Declaration of interests: none. 
618 Baptie, B., 2010. Seismogenesis and state of stress in the UK. Tectonophysics, 482(1), pp. 150-159.

619 Barker, J. et al., 2000. Hydrogeothermal studies in the United Kingdom. Quarterly Journal of

620 Engineering Geology and Hydrogeology,, Volume 33, p. 41-58.

621 BGS, 1986. Hydrogeological map of Fife \& Kinross including parts of hydrometric areas 14, 15, 16,

62217 and 18., s.1.: British Geological Survey.

623 Bonnet, E. et al., 2001. Scaling of fracture systems in geological media. Reviews of Geophysics, 39(3), 624 p. $347-83$.

Browne, M., Hargreaves, R. \& Smith, I., 1985. The Upper Palaeozoic Basins of the Midland Valley of Scotland, s.l.: British Geological Survey.

Browne, M., Smith, R. \& Aitken, A., 2002. Stratigraphical framework for the Devonian (Old Red Sandstone) rocks of Scotland south of a line from Fort Willam to Aberdeen, s.1.: British Geological Survey Report.

Busby, J., 2010. Geothermal prospects in the United Kingdom. s.1., Proceedings World Geothermal Congress 2010, Bali, Indonesia, 25-29 April 2010.

Caine, J., Evans, J. \& Forster, C., 1996. Fault zone architecture and permeability structure. Geology, 24(11\#), p. 1025-1028.

Cherubini, Y., Cacace, M., Scheck-Wenderoth, M. \& Noack, V., 2014. Influence of major fault zones on 3-D coupled fluid and heat transport for the Brandenberg region (NE German Basin). Geothermal Energy Science, Volume 2, pp. 1-20.

Childs, C. et al., 2009. A geometric model of fault zone and fault rock thickness variation. Journal of Structural Geology, Volume 31, p. 118 - 127.

639 Dumas, P. \& Bartosik, A., 2014. GeoDH: D2.2 Geothermal DH Potential in Europe, s.1.: (European 640 Geothermal Energy Council).

641 Evans, J., Forster, C. \& Goddard, J., 1997. Permeability of fault-related rocks, and implications for 642 hydraulic structure of fault zones. Journal of Structural Geology, 19(11), p. 1393 to 1404.

643 Faulkner, D. et al., 2010. A review of recent developments concerning the structure, mechanics and 644 fluid flow properties of fault zones. Journal of Structural Geology, Volume 32, pp. 1557-1575.

645 Forster, C. \& Evans, J., 1991. Hydrogeology of Thrust Faults and Crystalline Thrust Sheets: Results 646 of Combined Field and Modeling Studies. Geophysical Research Letters, Volume 18, pp. 979-982. 
647 Fraser Harris, A., McDermott, C., Kolditz, O. \& S, H., 2015. Modelling groundwater flow changes 648 due to thermal effects of radioactive waste disposal at a hypothetical repository site near Sellafield, 649 UK. Environmental Earth Sciences, 74(2), pp. 1589-1602.

650 Gaus, I. \& Ó Dochartaigh, B., 2000. Conceptual modelling of data-scarce aquifers in Scotland: the 651 sandstone aquifers of Fife and Dumfries. Geological Society, London, Volume 182, pp. 157-168.

652 Geuzaine, C. \& Remacle, J., 2009. Gmsh: a three-dimensional finite element mesh generator with 653 built-in pre- and post-processing facilities. International Journal for Numerical Methods in 654 Engineering, 79(11), pp. 1309-1331.

655 Gillespie, M., Crane, E. \& Barron, H., 2013. Deep Geothermal Energy Potential in Scotland. British 656 Geological Survey Commissioned Report CR/12/131, p. 129pp.

657 Heidbach, O. et al., 2008. The World Stress Map database release 2008. Commission for the 658 Geological Map of the World.

659 Holzer, T., Davis, S. \& Lofgren, B., 1979. Faulting caused by groundwater extraction in southcentral 660 Arizona. Journal of Geophysical Research: Solid Earth, 84(82), pp. 603-612.

661 MacDonald, A., Ball, D. \& Ó Dochartaigh, B., 2004. A GIS of aquifer productivity in Scotland: 662 Explanatory notes, CR/04/047N, s.1.: British Geological Survey.

663 MacQueen, J., 1967. Some methods for classification and analysis of multivariate observations. 664 Proceedings of the Fifth Berkeley Symposium on Mathematical Statistics and Probability, Volume 665 Vol 1: Statistics, pp. 281-297.

666 Mauldon, M., 1998. Estimating mean fracture trace length and density from observations in convex 667 windows. Rock Mechanics and Rock Engineering, 31(4), pp. 201-216.

668 McCoss, A., 1987. Geometry and Kinematics of Transpression and Transtension, s.1.: A thesis 669 submitted for the Degree of Doctor of Philosophy of the Faculty of Science, Queen's University 670 Belfast.

671 McDermott, C. I. et al., 2006a. Investigation of coupled hydraulic-geomechanical processes at the 672 KTB site: pressure-dependent characteristics of a long-term pump test and elastic interpretation using 673 a geomechanical facies model. Geofluids, Volume 6, p. 67-81.

674 McDermott, C. I. et al., 2006. Investigation of coupled hydraulic-geomechanical processes at the 675 KTB site: pressure-dependent characteristics of a long-term pump test and elastic interpretation using 676 a geomechanical facies model. Geofluids, Volume 6, p. 67-81. 
677 McDermott, C., Randriamanjatosoa, A., Tenzer, H. \& Kolditz, O., 2006b. Simulation of heat

678 extraction from crystalline rocks: The influence of coupled processes on differential reservoir cooling.

679 Geothermics, Volume 35, p. 321-344.

680 Midland Valley, 2015. Move 2015 Manual, Glasgow: s.n.

681 Neuman, S., 1994. Generalized scaling of permeabilities: validation and effect of support scale..

682 Geophysical Research Letters, Volume 21, p. 349-52.

683 Ó Dochartaigh, B., 2004. The Physical properties of the Upper Devonian/Lower Carboniferous

684 aquifer in Fife, Internal Report IR/04/003, s.1.: Groundwater Systems and Water Quality Programme,

685 BGS.

686 Ó Dochartaigh, B., Doce, D., Rutter, H. \& MacDonald, A. M., 2011. User guide : Aquifer

687 Productivity (Scotland) GIS Datasets (OR/11/065), s.1.: British Geological Survey.

688 Oda, M., 1985. Permeability tensor for discontinuous rock masses. Geotechnique, 35(4), pp. 483-495.

689 Pratt, H., Swolfs, H., Brace, W. \& Black, A., 1977. Elastic and transportproperties of in situ jointed

690 granite. International Journal of Rock Mechanics and Mining Sciences \& Geomechanics Abstract,

691 Volume 14, pp. 35-45.

692 Priest, S., 1993. Discontinuity Analysis for Rock Engineering. London, United Kingdom: Chapman \& 693 Hall.

694 Rippon, J., Read, W. \& Park, R., 1996. The Ochil Fault and the Kincardine basin: key structures in the 695 tectonic evolution of the Midland Valley of Scotland. Journal of the Geological Society, Volume 153, 696 pp. 573-587.

697 Robinson, R. et al., 2016. Geothermal Energy Challenge Fund: the Guardbridge Geothermal

698 Technology Project, s.l.: St. Andrews University.

699 Talwani, P., Cobb, J. \& Schaeffer, M., 1999. In situ measurements of hydraulic properties of a shear

700 zone in northwestern South Carolina. Journal of Geophysical Research B: Solid Earth, Volume 104,

701 p. 14993-15004.

702 Watanabe, N. et al., 2010. Uncertainty analysis of thermo-hydro-mechanical coupled processes in

703 heterogeneous porous media. Computational Mechanics, Volume 45, p. 263-280.

704 Watkins, H., Bond, C., Healy, D. \& Butler, R., 2015. Appraisal of fracture sampling methods and a 705 new workflow to characterise heterogeneous fracture networks at outcrop. Journal of Structural 706 Geology, Volume 72, pp. 67-82. 
707 Yerkes, R. \& Castle, R., 1976. Seismicity and faulting attributable to fluid extraction. Engineering 708 Geology, 10(2-4), pp. 151-167. 